Chapter 5

\title{
Inoculation Methods of Bradyrhizobium japonicum on Soybean in South-West Area of Japan
}

\author{
Takeo Yamakawa and Yuichi Saeki \\ Additional information is available at the end of the chapter \\ http://dx.doi.org/10.5772/52183
}

\section{Introduction}

Inoculation with efficient rhizobia at the ordinary dose does not increase appreciably the seed yield of soybean because the occupation ratio of the inoculated rhizobial strains in the nodules is very low due to competition with less efficient indigenous rhizobia [1, 2]. In order to increase the seed yield by rhizobial inoculation, the occupation ratio of the inoculated strains must be increased. The increase of the occupation ratio has been examined from various viewpoints such as improvement of inoculation method [3]. For the screening of efficient and competitive strains, a large number of useful strains had been isolated from mutagenized and recombinant rhizobia $[4,5,6]$.

Furthermore, Williams and Lynch [7] who identified a non-nodulating line of soybean among the progenies from the cross between cvs. Lincoln and Richard, showed that the abnormal nodulation reaction was controlled by a single recessive gene of the host plant, $r j_{1}$. Thereafter, cv. Hardee was found to nodulate ineffectively with Bradyrhizobium japonicum belonging to the strains 3-24-44 and 122 serogroups [8, 9]. It was demonstrated that the ineffective nodulation was controlled by a host dominant gene, $R j_{2}$. Furthermore, this cultivar was found to nodulate ineffectively with the B. elkanii strain 33 due to the presence of another $R j$-gene, $R j_{3}$ [10]. Cvs. Hill and Amsoy 71 harbor a gene $\left(R j_{4}\right)$ that was responsible for the ineffective nodulation. These $R j_{4}$-cultivars were nodulated ineffectively with B. elkanii strain 61 [11]. Soybean plants harboring these $R j$-genes ( $R j$-cultivars) were considered to restrict effective nodulation with appropriate serogroups of strains and to prefer certain types of rhizobia for nodulation. If this assumption holds true, planting of $R j$-cultivars could increase the populations of rhizobial strains highly compatible with those cultivars in soils. Therefore, the relationship between the Rj-genotypes of soybean and the preference of the Rj-cultivars for various types of Bradyrhizobium strain was examined [12, 13]. These Bradyrhizobium 
strains were classified into three nodulation types, type A, B, and C, based on the compatibility with Rj-cultivars. Nodulation type A strains nodulated with almost all the cultivars except for the $r j_{1}$-ones (non-nodulating lines) and were preferred by non- $R j$-ones. Type B or type $\mathrm{C}$ strains nodulated soybean cultivars other than the $R j_{2} R j_{3}$-ones or $R j_{4}$-ones, respectively except for $r j_{1}$-ones and were preferred by $R j_{4}$-ones or $R j_{2} R j_{3}$-ones, respectively.

This chapter deals with the developmental process and experimental trial of inoculation methods using effective Bradyrhizobium strains and various Rj-genotypes to increase the yield of soybean.

\section{Isolation of $R j_{2} R j_{3} R j_{4}-$ Genotypes from progenies of a cross between soybean cvs. IAC-2 $\left(R j_{2} R j_{3}\right)$ and hill $\left(R j_{4}\right)$}

In order to analyze in more detail the relationship between the $R j$-genotype of soybean and the preferences of $R j$-cultivars for various types of rhizobia, the preferences of the soybean cultivars harboring both $R j_{2^{-}}$and $R j_{4}$-genes for nodulation with Bradyrhizobium strains should be studied. For this purpose, the isolation of $R j_{2} R j_{4}$-lines from the cross between the $R j_{2}$-cultivar IAC-2 and the $R j_{4}$-cultivar Hill was firstly conducted. Secondly, the isolation of $R j_{2} R j_{3} R j_{4}$-lines from progenies of $R j_{2} R j_{4}$-lines was conducted [14, 15]. This section deals with the processes of isolation of $R j_{2} R j_{4}$-lines and $R j_{2} R j_{3} R j_{4}$-lines. Furthermore, the preference of various $R j$-genotypes for rhizobial strains was analyzed in greater detail.

\subsection{Materials and methods}

Detection of $R j_{2}$ - and $R j_{4}$-genes in progenies from the cross of cvs. IAC-2 and Hill: Soybean (Glycine max L. Merr.) cvs. IAC-2 $\left(R j_{2} R j_{3}\right)$ and Hill $\left(R j_{4}\right)$ were crossed. Twenty-three seeds were obtained and used to isolate the progenies homozygous for the $R j_{2^{-}}$and $R j_{4^{-}}$ genes. Bradyrhizobium japonieum strains Is-80 (nodulation type A), Is-1 (type B), and Is-34 (type C), which were isolated and characterized in a previous study, were used to detect the $R j_{2}-$ and $R j_{4}$-genes (Ishizuka et al. 1991a). Soybean cv. CNS $\left(R j_{2} R j_{3}\right)$ was used instead of cv. IAC-2 $\left(R j_{2} R j_{3}\right)$ in inoculation tests. Seeds of progenies from the cross were sterilized with sodium hypochlorite solution $\left(30 \mathrm{~g} \mathrm{~L}^{-1}\right)$, sown in sterilized vermiculite wetted with the nitrogen-free culture solution used in the previous study (Ishizuka et al. 1991a), inoculated with the combined inoculum of broth cultures of B. japonicum strains Is- 1 and Is-34, and grown in a phytotron at $25^{\circ} \mathrm{C}$ under natural light conditions. Four weeks after sowing, the plants were harvested and examined for the nodulation reaction. Non-nodulated and ineffectively nodulated plants which formed small nodule-like structures with a white center, were selected as a genotype harboring both $R j_{2}$ - and $R j_{4}$-genes at least heterozygously. Although the parent cultivar IAC-2 harbors the $R j_{3}$-gene in addition to $R j_{2}$-gene, it was not used because the isolation of progenies homozygous for the three genes was very complicated.

Detection of $R j_{3}$-gene in $R j_{2} R j_{4}$-lines: To detect the $R j_{3}$-gene, $R j_{2} R j_{4}$-lines characterized, A250, B340, B345, B346, B349, B410, C242, C244, C247, and C249, and cvs. Bragg (non-Rj), 
D-51 $\left(R j_{3}\right)$, IAC-2, CNS, and Hardee $\left(R j_{2} R j_{3}\right)$, and Akisengoku and Hill $\left(R j_{4}\right)$ were used. The $R j$-genotypes are indicated in parentheses $[12,14]$. To examine the preference of $R j$-cultivars for B. japonicum for nodulation, Bragg and Akisirome (non- $R j)$, IAC-2 $\left(R j_{2} R j_{3}\right)$, and Hill $\left(R j_{4}\right)$, A250 and C242 $\left(R j_{2} R j_{4}\right)$ were grown in pots filled with gray lowland alluvial soils. Soybean seeds used were harvested at Kyushu University Farm in 1992. B. japonicum USDA33 and USDA110 obtained from the USDA Beltsville Rhizobium Culture Collection, USA, and B. japonicum Is-1 and Is-34 were used. These strains were stored at $4^{\circ} \mathrm{C}$ on yeast extract mannitol agar (YMA) plate, and were cultured in yeast extract mannitol broth [16] on a rotary shaker (100 rpm) at $30^{\circ} \mathrm{C}$ for 7 days. These cultures were diluted to $1 / 200$ (ca. $10^{7}$ cells $\mathrm{mL}^{-1}$ ) with sterile saline water $\left(9 \mathrm{~g} \mathrm{NaCl} \mathrm{L}^{-1}\right)$ immediately before inoculation. Is-1, USDA33, or Is-34 cannot form effective nodules on soybean harboring the $R j_{2} R j_{3}{ }^{-}, R j_{3}$ - or $R j_{4}$-gene, respectively $[10,14]$. Seeds of the $R j_{2} R j_{4}$-lines and various $R j$-cultivars were sterilized by immersion in a sodium hypochlorite solution ( $50 \mathrm{~g} \mathrm{~L}^{-1}$ as active chlorine) for $5 \mathrm{~min}$, washed with ethanol, rinsed five times in sterile water. In the Erlenmeyer flask method, two seeds were sown in a sterilized Erlenmeyer flask containing $110 \mathrm{~mL}$ of vermiculite and $60 \mathrm{~mL}$ of nutrient solution consisting of $1.6 \mathrm{mM} \mathrm{K}_{2} \mathrm{HPO}_{4}, 2.0 \mathrm{mM} \mathrm{CaCl}_{2}, 2.5 \mathrm{mM} \mathrm{MgSO}_{4}$, and $0.5 \mathrm{mM} \mathrm{NH}_{4} \mathrm{NO}_{3}$. In the porcelaneous pot method, 14 seeds were sown in a porcelaneous pot containing $2.8 \mathrm{~L}$ of vermiculite and 1.4 L of nutrient solution. The flasks or pots were autoclaved $\left(121^{\circ} \mathrm{C}, 20 \mathrm{~min}\right)$. Five milliliters of USDA33 cell suspension per seed was inoculated. Plants were grown in a Phytotron at $25^{\circ} \mathrm{C}$ and $70 \%$ relative humidity under natural light. Three or four weeks after planting, the plants were harvested and examined for the number, size, and shape of the nodules to estimate the effectiveness of the nodules. A globular nodule larger than $1 \mathrm{~mm}$ in size was referred to as an effective nodule, and a nodule appearing as a protuberance smaller than $1 \mathrm{~mm}$ in size was referred to as an ineffective one.

Isolation of B. japonicum from nodules: Six weeks after planting in a/5,000 porcelain Wagner pots, plants were harvested and examined for the number of nodules. Approximately 12 to 14 nodules for each independent pot after 4 weeks of plant growth were collected from soybeans grown in soil. The nodules were immersed in $90 \%$ ethanol for $1 \mathrm{~min}$. Then the nodules were transferred to a solution of $5 \%$ hydrogen peroxide, soaked for $5 \mathrm{~min}$ and washed with sterile saline water three times. The nodules were crushed in a sterile test tube with a sterile glass rod and diluted with sterile saline water. The bacteroid suspension was streaked with a sterile bamboo stick on YMA plates containing Congo red $\left(25 \mathrm{mg} \mathrm{L}^{-1}\right)$. The YMA plates were incubated for one week at $30^{\circ} \mathrm{C}$. The colonies grown on the plates and the residual bacteroid suspension were subjected to the Indole acetic acid (IAA)-producing ability assay and serological test, respectively.

Serological identification of baeteroids in nodules: The antisera developed against the somatic antigens of the B. japonicum strains Is-1, Is-34, USDA110 and B. elkanii strain USDA33 used in this study were prepared as in the previous study [13]. The antisera were diluted to $1 / 200$ and $1 / 400$ with saline water immediately before use. For the serological test, the nodules were harvested, washed and put into a test tube containing saline water. The test tube was heated in boiling water for $30 \mathrm{~min}$. After cooling, the nodules were transferred to small test tubes, one nodule in each tube, and crushed with a round-ended glass rod. Then the 
bacteroids were dispersed using a vibrator with a small amount of saline water containing sodium azide $\left(0.5 \mathrm{~g} \mathrm{~L}^{-1}\right)$. After precipitation of the nodule debris, each drop of the bacteroid suspension and the diluted antiserum were put into a well of a micro-test assay plate (Becton Dickinson and Co., USA) using fresh Pasteur pipettes, covered with a thin polyethylene film and shaken gently. The plate was incubated at $37^{\circ} \mathrm{C}$ for $2 \mathrm{~h}$ and then stored in a cold room $\left(4^{\circ} \mathrm{C}\right)$ overnight. The agglutination reaction was checked on the next day by comparison with the bacteroid-saline control.

IAA-producing ability: The IAA-producing ability was estimated basically by the methods of Minamisawa et al. [17]. Single colony of isolates on the YMA plates was suspended into $5 \mathrm{~mL}$ of sterile saline water and a drop of the suspension was poured into 2.5 $\mathrm{mL}$ of the Tris-YMRT ( $\mathrm{pH}$ 6.8) broth medium [18] containing $0.3 \mathrm{mM}$ L-tryptophan. The cultures were incubated for one week at $30^{\circ} \mathrm{C}$ on a rotary shaker at a rate of $100 \mathrm{rpm}$, and the IAA concentration was determined colorimetrically by the addition of $5 \mathrm{~mL}$ of Salkowski's reagent [19].

\subsection{Results and discussion}

Isolation of $R j_{2} R j_{4}$-lines: For the verification of the above assumption, the nodulation reactions of the F4 progenies from selected F3 plants with the combined inoculum were examined (Table 1). All the F4 progenies from C3-1, -3 , and -5 plants nodulated effectively and produced more than five nodules per plant. Within the limits of the authors' preliminary experiments, soybean plants inoculated with incompatible B. japonicum strains had never produced more than two nodules under natural light conditions in winter, so that these plants were assumed to harbor either $r j_{2}$ or $r j_{4}$ homozygously. Since the ratios of effectively nodulated progenies from the F3 plants, lines A2-4 and C3-4 were approximately 0.44, the expected ratio according to Mendel's laws, these F4 plants were assumed to belong to the genotype $R j_{2} r j_{2} R j_{4} r j_{4}$ [14]. Thus, these five lines (F4 generation) were omitted for further selection. In order to predict the genotypes of the remaining lines, A2-5, B3-4, C2-4, and C2-5, the bacteroids present in the nodules were identified serologically. The genotype of A2-5 was considered to be $R j_{2} R j_{2} R j_{4} r j_{4}$ because the ratio of effectively nodulated plants and the nodule number of the nodulated plants were 0.25 and more than five, respectively, and almost all the nodules were occupied by Is-34 [14]. On the other hand, the ratios of the nodulated progenies of the B3-4 and C2-4 plants were nearly 0.25 also, but the nodule numbers were only four per four and three plants, respectively, and half or three fourths of these were produced by other serotypic rhizobia than the inoculum strains.

Thirty-one plants of the F4 generation were harvested, and the seeds (F6 generation) of 22 plants were examined for their compatibility with B. japonicum Is-1 and 1s-34 by the method described above. The plants were classified based on the nodule number (Table 2), and it was eventually concluded that the progenies from line A2-5 segregated into the genotypes $R j_{2} R j_{2} R j_{4} R j_{4}$ and $R j_{2} R j_{2} R j_{4} r j_{4}$. The lines A2-50 and A2-53 belonged to the former and latter, respectively. Although line A2-52 may also belonged to the former genotype, the genotype of line A2-51 was not clearly revealed because five plants out of 20 plants formed more than four nodules and the soybean cvs. CNS $\left(R j_{2} R j_{3}\right)$ and Hill $\left(R j_{4}\right)$ formed six nodules per plant 
in this assay. Therefore, the lines A2-51, A2-52, and A2-53 were omitted. The progenies from line B3-4 could be considered to belong to the genotype $R j_{2} R j_{2} R j_{4} R j_{4}$ except for the lines B3-44 and B3-47. Though the lines B3-44 and B3-47 were also expected to belong to the same genotype as the other progenies of line B3-4, these were omitted for further examination to avoid the risk. All the tested progenies from line C2-4 were found to belong to the genotype $R j_{2} R j_{2} R j_{4} R j_{4}$ unlike those of line C2-5, based on the results shown in Table 2 . The facts described above indicate that 12 soybean lines homozygous for the $R j_{2}$ - and $R j_{4}$-genes were isolated from the cross cvs. IAC-2 $\left(R j_{2} R j_{3}\right) \times$ Hill $\left(R j_{4}\right)$. These lines showed some differences in physiological characteristics, for instance, hypocotyl color, stem length and maturity.

\begin{tabular}{cccccc}
\hline \multirow{2}{*}{ F3 plant } & $\begin{array}{c}\text { No. of plants } \\
\text { tested }\end{array}$ & \multicolumn{3}{c}{ Nodulation reaction of F. progeny } & $\begin{array}{c}\text { Ratio of effectively } \\
\text { nodulated plants }\end{array}$ \\
\cline { 2 - 5 } & 16 & 9 & $\mathrm{I}$ & $\mathrm{N}$ & 0.56 \\
A2-4 & 16 & 4 & 9 & 0 & 0.25 \\
A2-5 & 16 & 4 & 12 & 3 & 0.25 \\
B3-4 & 14 & 3 & 5 & 0 & 0.21 \\
C2-4 & 15 & 1 & 2 & 6 & 0.07 \\
C2-5 & 12 & 12 & 0 & 12 & 1.00 \\
C3-1 & 13 & 13 & 0 & 0 & 1.00 \\
C3-3 & 15 & 8 & 7 & 0 & 0.53 \\
C3-4 & 15 & 15 & 0 & 0 & 1.00 \\
C3-5 & 15 & 0 & 0 & \\
\hline
\end{tabular}

E, I, and $\mathrm{N}$ denote effective, ineffective, and non-nodulated, respectively

Table 1. Nodulation reactions of F4 progenies from the cross IAC-2 $\times$ Hill with the combined inoculum of $B$. japonicum strains Is-I and -34 .

Isolation of $R j_{2} R j_{3} R j_{4}$-lines: Soybean cultivar D-51 harboring the $R j_{3}$-gene frequently formed a small number of effective nodules and a large number of ineffective ones upon the inoculation of B. elkanii USDA33. Therefore, the criteria for harboring the $R j_{3}$-gene were determined as follows. When the ratio of ineffective to the total nodule number $(\mathrm{I} / \mathrm{T})$ exceeded 0.5 , it was assumed that the test plant harbored the $R j_{3}$-gene. Table 3 shows the nodulation of test plants inoculated with B. elkanii USDA33. Cvs. Bragg (non- $R j)$, Hill and Akisengoku $\left(R j_{4}\right)$ formed only effective nodules and not ineffective nodules. However, cvs. IAC-2, CNS, and Hardee $\left(R j_{2} R j_{3}\right)$ did not produce any effective nodules and formed 0.8 to 17.5 ineffective nodules per plant at 3-weeks after the inoculation of USDA33 using an Erlenmeyer flask. In cv. D-51 $\left(R j_{3}\right), 3.7$ effective and 30.0 ineffective nodules per plant were counted at 4-weeks after the inoculation using a porcelain pot. I/T ratio of all the cultivars harboring the $\mathrm{Rj}_{3}$ gene exceeded 0.5 which corresponded to the criterion for the detection of the $R j_{3}$-gene. $\mathrm{Al}$ so, the I/T ratio of all the $R j_{2} R j_{4}$-lines tested here ranged from 0.6 to 0.9 for the plants grown for 3 weeks and a value of 1.0 was recorded at 4 weeks after inoculation. Based on these results, it was concluded that all the $R j_{2} R j_{4}$-lines tested here harbored the $R j_{3}$-gene and displayed the $R j_{2} R j_{3} R j_{4}$-genotype. Also it may be necessary for the plant to grow for 4 weeks for the identification of the $R j_{3}$-gene, because the growth of ineffective nodules was delayed 
compared to that of the effective nodules and counting and discrimination were difficult on plants grown for only 3 weeks (Table 3).

\begin{tabular}{|c|c|c|c|c|c|c|c|c|c|}
\hline \multirow{2}{*}{ Line } & \multirow{2}{*}{ Inoculum } & \multicolumn{6}{|c|}{ Plant number ${ }^{\mathrm{a}}$} & \multicolumn{2}{|c|}{ Nodule number } \\
\hline & & 0 & 1 & 2 & 3 & $4<$ & Total & $E$ & I \\
\hline $\mathrm{A} 2-50$ & $\mathrm{C}$ & 18 & 2 & 0 & 0 & 0 & 20 & 0.1 & 0 \\
\hline$\overline{\mathrm{A} 2-51}$ & $\mathrm{C}$ & 8 & 5 & 1 & 1 & 5 & 20 & 1.7 & 0.2 \\
\hline $\mathrm{A} 2-52$ & $\mathrm{C}$ & 11 & 5 & 3 & 0 & 1 & 20 & 0.8 & 0 \\
\hline $\mathrm{A} 2-53$ & $\mathrm{C}$ & 0 & 0 & 1 & 0 & 13 & 14 & 8.1 & 0 \\
\hline B3-40 & $\mathrm{C}$ & 10 & 8 & 2 & 0 & 0 & 20 & 0.6 & 0 \\
\hline$\overline{\mathrm{B} 3-44}$ & $\mathrm{C}$ & 10 & 6 & 2 & 2 & 0 & 20 & 0.8 & 0 \\
\hline B3-45 & $\mathrm{C}$ & 13 & 4 & 3 & 0 & 0 & 20 & 0.5 & 0 \\
\hline$\overline{B 3-46}$ & $\mathrm{C}$ & 8 & 11 & 1 & 0 & 0 & 20 & 0.7 & 0.1 \\
\hline B3-47 & $\mathrm{C}$ & 7 & 8 & 3 & 1 & 1 & 20 & 1.1 & 0 \\
\hline B3-49 & $\mathrm{C}$ & 9 & 8 & 3 & 0 & 0 & 20 & 0.2 & 0 \\
\hline$\overline{\mathrm{B} 3-410}$ & $\mathrm{C}$ & 17 & 3 & 0 & 0 & 0 & 20 & 0.7 & 1.8 \\
\hline $\mathrm{C} 2-40$ & $\mathrm{C}$ & 18 & 2 & 0 & 0 & 0 & 20 & 0.1 & 2.9 \\
\hline$\frac{\mathrm{C} 2-42}{\mathrm{C} 2-42}$ & $\mathrm{C}$ & 17 & 3 & 0 & 0 & 0 & 20 & 0.2 & 1.7 \\
\hline$\overline{\mathrm{C} 2-44}$ & C & 15 & 5 & 0 & 0 & 0 & 20 & 0.3 & 1.3 \\
\hline$\overline{\mathrm{C} 2-47}$ & C & 14 & 6 & 0 & 0 & 0 & 20 & 0.3 & 0.9 \\
\hline$\overline{\mathrm{C} 2-48}$ & C & 20 & 0 & 0 & 0 & 0 & 20 & 0 & 0 \\
\hline$\overline{\mathrm{C} 2-49}$ & $\mathrm{C}$ & 13 & 6 & 1 & 0 & 0 & 20 & 0.4 & 0 \\
\hline $\mathrm{C} 2-50$ & $\mathrm{C}$ & 8 & 2 & 1 & 1 & 8 & 20 & 2.6 & 0.8 \\
\hline $\mathrm{C} 2-51$ & C & 0 & 0 & 2 & 0 & 17 & 19 & 6.7 & 0 \\
\hline $\mathrm{C} 2-52$ & C & 1 & 0 & 0 & 2 & 16 & 19 & 5.5 & 0 \\
\hline $\mathrm{C} 2-53$ & C & 9 & 2 & 2 & 2 & 5 & 20 & 2 & 0.6 \\
\hline $\mathrm{C} 2-55$ & C & 1 & 0 & 1 & 1 & 17 & 20 & 6.2 & 0 \\
\hline CNS & $\mathrm{C}$ & 0 & 0 & 0 & 0 & 6 & 6 & 6.2 & 0 \\
\hline Hill & C & 0 & 1 & 0 & 0 & 5 & 6 & 5.8 & 0 \\
\hline CNS & Is-1 & 4 & 0 & 0 & 0 & 0 & 3 & 0 & 0 \\
\hline Hill & Is-1 & 0 & 0 & 0 & 0 & 4 & 4 & 5.8 & 0 \\
\hline CNS & Is-34 & 0 & 0 & 0 & 0 & 3 & 3 & 9.3 & 0 \\
\hline Hill & Is- 34 & 4 & 0 & 0 & 0 & 0 & 4 & 0 & 0 \\
\hline
\end{tabular}

C: combined inoculum of Is-1 and Is-34. Underlined part: line with genotype $R j_{2} R j_{2} R j_{4} R j_{4}$. E and I: number of effective and ineffective nodule per plant, respectively. ${ }^{a}$ Number of plants which produced nodules with the number shown below.

Table 2. Nodulation of F6 progenies from the cross between soybean cvs. IAC-2 and Hill inoculated with B. japonieum Is-I and -34 .

Preference of $R j_{2} R j_{3} R j_{4}$-lines for indigenous rhizobia: Table 4 shows the nodule numbers of soybean plants grown in pots containing Chikugo soil. The nodules formed on the roots of all the soybean plants grown in this soil were all effective. Non-Rj-cultivars, Akisirome and Bragg formed a relatively large number of nodules on the tap roots and the number was not significantly different from that on the lateral roots. In the case of the Rj-cultivars, however, the nodule number of the tap roots was markedly lower than that of the lateral roots, that is, all the Rj-cultivars formed 3.0 to 4.3 nodules on the tap roots and 16.3 to 24.3 nodules on the lateral roots per plant. These data clearly indicate that nodule formation in the non- $R j$ cultivars occurs earlier than in the $R j$-cultivars, because nodule formation occurred first on the tap roots and then gradually developed on the lateral roots with the progression of growth. 
The difference in the onset of nodule formation between non- $R j$ - and $R j$-cultivars may be due to the difference in populations of compatible rhizobial strains with both genotypes. Also, although the $R j_{2} R j_{3} R j_{4}$-genotype was derived from the cross between $R j_{2} R j_{3}$ - and $R j_{4}$-genotype in order to restrict the nodulation with undesirable strains, the difference in the nodulation ability was not appreciable among the three $R j$-genotypes. Therefore, it is suggested that the $R j_{2} R j_{3} R j_{4}$-genotype cannot decrease the ability of nodule formation but may increase the preference of certain types of rhizobia for nodulation.

\begin{tabular}{|c|c|c|c|c|c|c|c|}
\hline \multirow{3}{*}{ Cultivar or line } & \multicolumn{5}{|c|}{ Nodule number } & \multirow{3}{*}{$\mathrm{I} / \mathrm{T}$} & \multirow{3}{*}{$\begin{array}{l}R j_{3-} \\
\text { gene }\end{array}$} \\
\hline & & Effective & & Ineffective & Total & & \\
\hline & TR & LR & WR & (I) & $(\mathrm{T})$ & & \\
\hline \multicolumn{8}{|l|}{$R j$-cultivar } \\
\hline Bragg* & 1.2 & 1.5 & 2.7 & 0.0 & 2.7 & 0.0 & - \\
\hline IAC-2 & 0.0 & 0.0 & 0.0 & 17.5 & 17.5 & 1.0 & + \\
\hline $\mathrm{CNS}$ & 0.0 & 0.0 & 0.0 & 5.6 & 5.6 & 1.0 & + \\
\hline Hardee & 0.0 & 0.0 & 0.0 & 0.8 & 0.8 & 1.0 & + \\
\hline D-51* & 0.1 & 3.6 & 3.7 & 30.0 & 33.7 & 0.9 & + \\
\hline Hill & 0.5 & 4.7 & 5.2 & 0.0 & 5.2 & 0.0 & - \\
\hline Akisengoku & 2.2 & 3.8 & 6.0 & 0.0 & 6.0 & 0.0 & - \\
\hline \multicolumn{8}{|l|}{$R i_{2} R j_{4}$-line } \\
\hline $\mathrm{A} 250$ & 0.0 & 0.6 & 0.6 & 3.9 & 4.5 & 0.9 & + \\
\hline $\mathrm{A} 2 \mathrm{~S} 0^{*}$ & 0.1 & 0.5 & 0.6 & 28.1 & 28.7 & 1.0 & + \\
\hline B $340 *$ & 0.0 & 0.0 & 0.0 & 32.8 & 32.8 & 1.0 & + \\
\hline B $345^{*}$ & 0.0 & 0.0 & 0.0 & 16.8 & 16.8 & 1.0 & + \\
\hline B346* & 0.0 & 0.0 & 0.0 & 21.4 & 21.4 & 1.0 & + \\
\hline B $347^{*}$ & 0.0 & 0.0 & 0.0 & 17.6 & 17.6 & 1.0 & + \\
\hline B349* & 0.0 & 0.0 & 0.0 & 37.6 & 37.6 & 1.0 & + \\
\hline $\mathrm{B} 410^{*}$ & 0.0 & 0.5 & 0.5 & 38.3 & 38.8 & 1.0 & + \\
\hline $\mathrm{C} 242$ & 0.1 & 0.9 & 1.0 & 1.2 & 2.2 & 0.5 & + \\
\hline $\mathrm{C} 242 *$ & 0.0 & 0.2 & 0.2 & 24.9 & 25.1 & 1.0 & + \\
\hline $\mathrm{C} 244$ & 0.2 & 2.2 & 2.4 & 3.9 & 6.3 & 0.6 & + \\
\hline $\mathrm{C} 244^{*}$ & 0.0 & 0.1 & 0.1 & 28.4 & 28.5 & 1.0 & + \\
\hline $\mathrm{C} 247$ & 0.2 & 0.6 & 0.8 & 5.5 & 6.3 & 0.9 & + \\
\hline C249 & 0.2 & 1.2 & 1.4 & 8.6 & 10.0 & 0.9 & + \\
\hline C249* & 0.1 & 0.2 & 0.3 & 42.1 & 42.4 & 1.0 & + \\
\hline
\end{tabular}

Table 3. Identification of $R j_{3}$-gene in $R j_{2} R j_{4}$-lines and $R j$-cultivars with inoculum of $B$. elkanii USDA33.

Agglutination reaction with the antiserum against USDA110 was assayed with a bacteroid suspension of nodules from soybean plants grown in soil. Isolates separated from the residual bacteroid suspension were used for the assay of IAA-producing ability. Table 5 shows that the nodule occupancy rate of serotype 110, the bacteroid suspension of which reacted positively with the antiserum against USDA110, was significantly higher in the $R j_{2} R j_{3} R j_{4^{-}}$ genotype than in the other genotypes, i.e. non- $R j^{-}, R j_{2} R j_{3}{ }^{-}$, and $R j_{4}$-cultivars. Furthermore, C242 in the $R j_{2} R j_{3} R j_{4}$-genotype showed significantly lower ratios of IAA forming isolates than in the other genotypes but A250 in this genotype showed the same ratios as those in other genotypes. Based on the above results, the $R j_{2} R j_{3} R j_{4}$-genotype of soybean was consid- 
ered to nodulate more actively serogroup USDA 110 of rhizobia which contains Hup ${ }^{+}$strains at high rates for nodulation compared with the other genotypes.

Further studies should be carried out to determine whether the $R j_{2} R j_{3} R j_{4}$-gene is able to repress infection with B. elkanii which does not contain $\mathrm{Hup}^{+}$strains but contains rhizobitoxine-producing strains [20]. Nevertheless, the $R j_{2} R j_{3} R j_{4}$-genotype of soybean is superior to non- $R j^{-}, R j_{2} R j_{3}$ - and $R j_{4}$-genotypes in that it prefers more active rhizobial strains forming efficient nodules for nitrogen fixation. However, it remains to be determined whether the $R j_{2} R j_{3} R j_{4}$-genotype is superior to other $R j$-genotypes in terms of nodule occupancy of inoculum strain in field experiments using B. japonicum USDA 110 as effective inoculum strain.

\begin{tabular}{llccc}
\hline Cultivar or line & $R j$-genotype & Tap root & Lateral root & Whole root \\
\hline Akisirome & non- $R j$ & 18.8 & 26.0 & 44.8 \\
Bragg & non- $R j$ & 8.8 & 9.8 & 18.6 \\
IAC-2 & $R j_{2} R j_{3}$ & 3.0 & 16.3 & 19.3 \\
Hill & $R j_{4}$ & 4.3 & 24.3 & 28.6 \\
A250 & $R j_{2} R j_{3} R j_{4}$ & 3.5 & 17.5 & 21.0 \\
C242 & $R j_{2} R j_{3} R j_{4}$ & 4.0 & 21.0 & 25.0 \\
\hline
\end{tabular}

Data show a mean of 4-plants

Table 4. Number of nodules in soybean plants grown in pots containing gray soils of Kyushu Agricultural Experiment Station.

\begin{tabular}{|c|c|c|c|c|}
\hline \multirow[b]{2}{*}{ Cultivar or line } & \multicolumn{2}{|c|}{ Serotype 110} & \multicolumn{2}{|c|}{ IAA formation } \\
\hline & $\begin{array}{c}\text { Nodule occupancy } \\
(\%)\end{array}$ & $\begin{array}{c}\text { Statistical analysis } \\
(\mathrm{p}=0.05)\end{array}$ & $\begin{array}{c}\text { Nodule occupancy } \\
(\%)\end{array}$ & $\begin{array}{c}\text { Statistical analysis } \\
(\mathrm{p}=0.05)\end{array}$ \\
\hline Akisirome & 36 & $\mathrm{a}$ & 24 & $\mathrm{a}$ \\
\hline Bragg & 56 & b & 17 & abc \\
\hline IAC-2 & 39 & $\mathrm{a}$ & 15 & abcd \\
\hline Hill & 58 & b & 19 & $a b$ \\
\hline A250 & 73 & c & 11 & bcde \\
\hline C242 & 81 & c & 4 & e \\
\hline
\end{tabular}

Each figure in the column of nodule occupancy is significantly different at the $5 \%$ level by chi-square test when different letters are indicated in the column of statistical analysis. Twelve to 14 nodules or isolates from the tap roots and lateral roots of two plants in each independent pot were assayed. Data were calculated for the whole root and correspond to the mean of two replicate pots.

Table 5. Positive agglutination reaction with antiserum against USDA110 (serotype 110) of bacteroids in nodules of soybean plants grown in pots containing the soil of Kyushu Agricultural Experiment Station and IAA formation of isolates from the bacteroid suspension.

\section{Occupation of serogroup USDA110 in nodules of soybean plants harboring various $R j$-genes grown in a field}

In order to analyze in more detail the relationship between the $R j$-genotype of soybean and the preferences of $R j$-cultivars for various types of rhizobia, the preferences of the soybean cultivars harboring both $R j_{2^{-}}, R j_{3^{-}}$and $R j_{4}$-genes for nodulation with Bradyrhizobium strains 
should be studied. For this purpose, the isolation of $R j_{2} R j_{4}$-lines from the cross between the $R j_{2}$-cultivar IAC-2 and the $R j_{4}$-cultivar Hill was conducted. Furthermore, to analyze in greater detail the preference of various $R j$-genotypes for rhizobial strains, the isolation of $R j_{2} R j_{3} R j_{4}$-lines from the cross between the $R j_{2} R j_{3}$-cultivar IAC-2 and the $R j_{4}$-cultivar Hill was conducted [14, 15]. The $R j_{2} R j_{3} R j_{4}$-lines were predicted to be nodulated only by type A strains, such as B. japonicum USDA110. Thus, the competition with less efficient indigenous rhizobia in soils might be reduced by the use of the reciprocal relation between $R j$-cultivars and rhizobia. Therefore, the relationship between the Rj-genotypes of soybean and their preference for various types of rhizobia for nodulation was investigated.

\subsection{Materials and methods}

Plants: Soybean (Glycine max L. Merr.) cultivars Bragg and Akisirome (non-Rj), IAC-2, CNS, and Hardee $\left(R j_{2} R j_{3}\right)$, Hill, Fukuyutaka and Akisengoku $\left(R j_{4}\right)$, and B340, B349 and C242 $\left(R j_{2} R j_{3} R j_{4}\right)$ were used. The $R j$-genotypes are indicated in parentheses [14, 15].

Rhizobium:B. japonicum USDA110 was stored at $4{ }^{\circ} \mathrm{C}$ on YMA plate, and was cultured in $\mathrm{YMB}$ [16] on a rotary shaker $(100 \mathrm{rpm})$ at $30^{\circ} \mathrm{C}$ for 7 days. This culture was diluted to $1 / 200$ (ca. $10^{7}$ cells $\mathrm{mL}^{-\mathrm{I}}$ ) with saline water immediately before inoculation.

Plant cultivation: Field experiment was conducted on gray lowland soils of Kyushu University Farm, located in the northern flooded plain of Fukuoka Prefecture. The soil pH (soil: water ratio was $1: 2.5$ ) ranged from 6.9 to 7.3 . The field was $16 \mathrm{~m}$ long and $18 \mathrm{~m}$ wide. The row width and intra-row spacing were 70 and $20 \mathrm{~cm}$, respectively. Fused phosphate, calcium superphosphate, and potassium sulfate were applied at the time of plowing over the experimental field at the rates of $450 \mathrm{~kg} \mathrm{~N}, 150 \mathrm{~kg} \mathrm{P}_{2} \mathrm{O}_{5}$ and $200 \mathrm{~kg} \mathrm{~K}_{2} \mathrm{O}$ per ha, respectively. The seeds were sown at the rate of two seeds per hill on June 9, 1992. For each cultivar, the entire row (16 m long) was divided into four parts. The individual hills with alternative two parts were inoculated with $50 \mathrm{~mL}$ of $1 / 200$ diluted USDA110 culture ( 1 week old) at the rate of $5 \times 10^{8}$ cells per hill immediately after sowing and the individual hills with the other parts received $50 \mathrm{~mL}$ of saline water as control treatment. The experiment was conducted with two replications.

Sampling: In order to evaluate nodulation, the relative efficiency (RE) of nitrogen fixation and occupation ratio of the inoculum strain, two hills per soybean genotype in the inoculated or non-inoculated plots were harvested. The plant roots were washed with tap water. The growth stage corresponded to the vegetative stage at the time of the first sampling conducted during the period from July 28 to August 5, 1992. The second sampling was carried out in order to evaluate the occupation ratio of the inoculum strains on September 2, from the flowering to the pod elongation stages depending on the plant genotypes.

$\mathbf{H}_{2}$ evolution: Plant roots with nodules were severed at the cotyledonary node and individually placed in $200-\mathrm{mL}$ conical flasks. The flasks were sealed with a serum stopper. One milliliter of air was drawn out with a syringe, and was analyzed for the amount of hydrogen evolved from the nodules at 5 and $30 \mathrm{~min}$ after sealing by using a thermal conductivity gas chromatograph (GC-8A, Shimadzu, Kyoto, Japan) equipped with a stainless steel column (3 
$\mathrm{mm}$ in diameter, $2 \mathrm{~m}$ length). The column was filled with molecular sieve 5A, 60-80 mesh (Nacalai Tesque, Inc., Kyoto, Japan). Column and injector temperatures were 50 and $70^{\circ} \mathrm{C}$, respectively. Carrier gas was $\mathrm{N}_{2}$ (flow rate: $36 \mathrm{~mL} \mathrm{~min}^{-1}$ ).

Acetylene reduction activity (ARA): After the determination of $\mathrm{H}_{2}$ evolution, the flask containing roots with nodules was used for the ARA assay. ARA was assayed according to the methods of Haider et al. [21]. After the assay, the nodules were separated from the roots, weighed, and counted.

Relative efficiency (RE): $\mathrm{RE}$ of nitrogen fixation was calculated from the amount of $\mathrm{H}_{2}$ evolved and ARA as follows:

$\mathrm{RE}=1-\frac{\mathrm{H}_{2} \text { evolution }\left(\mu \text { molg } \mathrm{FW}^{-1} \mathrm{~h}^{-1}\right)}{\text { ARA }\left(\mu \text { molg } \mathrm{FW}^{-1} \mathrm{~h}^{-1}\right)}$

Serological test with antiserum USDA110 and occupation ratio: The nodules on the tap root and lateral roots of two hills of each genotype of soybean plants were separately collected into a test tube, with the addition of saline water $\left(8.5 \mathrm{~g} \mathrm{~L}^{-1}\right)$ containing $0.5 \mathrm{~g} \mathrm{~L}^{-1}$ of sodium azide and allowed to stand for $30 \mathrm{~min}$ in boiling water. The nodules were kept at $4^{\circ} \mathrm{C}$ until the serological test was performed. One hundred nodules per cultivar were used for the serological test, that is, a maximum number of 30 nodules from the tap root and the other nodules from the lateral roots per cultivar. The serological test was conducted with the antiserum against B. japonicum USDA110, according to the method described in a previous paper [15].

Occupation ratios of the tap, lateral and whole roots were expressed in percentages of positive nodules against antiserum USDA110 to all the nodules tested, respectively.

\subsection{Results and discussion}

The seeds were inoculated or irrigated immediately after sowing with $50 \mathrm{~mL}$ of diluted inoculum or saline water, as described above in the inoculation method of rhizobium. As a result, it was considered that the inoculum strain USDA110 was distributed to the cylindrical soil block in which the tap root of soybean seedlings could extend. Therefore, initial nodulation by USDA110 as inoculum was assumed to be limited to the upper part of the tap root. The effects of the inoculation of B. japonicum USDA110 on the nodulation of almost all the tested genotypes of soybean were not significant in terms of nodule number and fresh weight (FW) per plant, and nodule size (mg FW nodule ${ }^{-1}$ ), except for B349 among the soybeans with $R j_{2} R j_{3} R j_{4}$-genotypes [22]. These results suggest that the population of indigenous rhizobia in this field was not the limiting factor for nodulation.

Consequently, the information acquired from this experiment can be more useful for the cultivation of soybean than that derived from experimental results under controlled conditions and fields, in which the population of indigenous rhizobia is low. ARA did not show any significant difference between the inoculated and non-inoculated plants (Table 6). RE of the inoculated soybean plants tended to be higher than that of the non-inoculated ones in all the cultivars/lines. However, there was no significant difference in the effects among the Rj-gen- 
otypes of the host plants. Especially, RE of IAC-2, CNS $\left(R j_{2} R j_{3}\right)$ and B349 $\left(R j_{2} R j_{3} R j_{4}\right)$ increased significantly by USDA110 inoculation, reflecting the reduction in $\mathrm{H}_{2}$ evolution by Hup $^{+}$of USDA110. RE generally increased by inoculation of USDA110 (Hup ${ }^{+}$strain) and biological nitrogen fixation was considered to be enhanced. In four experiments conducted by Evans et al. [23], it was observed that the content of crude seed protein of soybean plants inoculated with the $\mathrm{Hup}^{+}$strain increased by $8.9 \%$ compared with the plants inoculated with Hup strains and that the REs (calculated from Evans's data) of the plants inoculated with $\mathrm{Hup}^{+}$and Hup strains were 0.94-1.00 and 0.56-0.79, respectively. As higher RE values were observed in the inoculated plants than in the non-inoculated plants, in spite of the lack of significant difference (Table 6), the occupation ratios of the serogroup USDA110 of rhizobia in the nodules of lateral roots were determined at the time of the first sampling (Table 7).

\begin{tabular}{|c|c|c|c|c|c|}
\hline$R j$-genotype & $\begin{array}{l}\text { Cultivar } \\
\text { and Line }\end{array}$ & $\begin{array}{l}\text { Inocu- } \\
\text { lation }\end{array}$ & $\begin{array}{c}\mathrm{H}_{2} \text { evol. } \\
\left(\mu \mathrm{mol} \mathrm{gFW}^{-1} \mathrm{~h}^{-1}\right)\end{array}$ & $\begin{array}{c}\text { ARA } \\
\left(\mu \mathrm{mol} \mathrm{gFW}^{-1} \mathrm{~h}^{-1}\right)\end{array}$ & $\mathrm{RE}$ \\
\hline \multirow[t]{4}{*}{ Non- $R j$} & Akisirome & + & $3.1^{\mathrm{ab}}$ & $7.1^{\mathrm{ab}}$ & 0.51 bcde \\
\hline & & - & 2.3 abcd & $3.8^{a b}$ & $0.4^{\text {def }}$ \\
\hline & Bragg & + & $2.5 \mathrm{abc}$ & $7.4^{\mathrm{a}}$ & $0.66^{\mathrm{abc}}$ \\
\hline & & - & $3.4^{\mathrm{a}}$ & $6.9^{\mathrm{ab}}$ & $0.5^{\text {bcde }}$ \\
\hline \multirow[t]{2}{*}{$R j_{2} R j_{3}$} & IAC-2 & + & 1.4 cde & $3.4^{b c}$ & 0.58 bcd \\
\hline & & - & 2.6 abc & $4{ }^{a b c}$ & $0.35^{\text {ef }}$ \\
\hline \multirow[t]{2}{*}{$R j_{2} R j_{3}$} & CNS & + & $0.6^{\mathrm{e}}$ & $2.2^{c}$ & $0.67^{\mathrm{ab}}$ \\
\hline & & - & 1.4 cde & $2.5^{c}$ & 0.46 cde \\
\hline \multirow[t]{2}{*}{$R j_{4}$} & Hill & + & 1.3 cde & $3.9^{\mathrm{abc}}$ & $0.66^{a b c}$ \\
\hline & & - & 1.8 bcde & $4.7^{\mathrm{abc}}$ & 0.63 abc \\
\hline \multirow[t]{2}{*}{$R j_{4}$} & Fukuyutaka & + & $0.6^{\mathrm{e}}$ & $2.4^{c}$ & $0.78^{a}$ \\
\hline & & - & 1.2 cde & $3^{b c}$ & $0.62 \mathrm{abc}$ \\
\hline \multirow[t]{2}{*}{$R j_{2} R j_{3} R j_{4}$} & B340 & + & 0.9 de & $2.6^{c}$ & $0.67^{\mathrm{ab}}$ \\
\hline & & - & $1.0 \mathrm{de}$ & $2.3^{c}$ & $0.55^{\text {bcd }}$ \\
\hline \multirow[t]{2}{*}{$R j_{2} R j_{3} R j_{4}$} & B349 & + & 0.7 e & $2^{c}$ & $0.63 \mathrm{abc}$ \\
\hline & & - & 1.7 bcde & $2.2^{c}$ & $0.24^{\mathrm{f}}$ \\
\hline \multirow{2}{*}{$R j_{2} R j_{3} R j_{4}$} & C242 & + & $0.6^{\mathrm{e}}$ & $1.4^{\mathrm{c}}$ & $0.55^{\text {bcd }}$ \\
\hline & & - & $0.6^{\mathrm{e}}$ & $1.3^{c}$ & 0.53 bcde \\
\hline
\end{tabular}

ARA and RE refer to the acetylene reduction activity and relative efficiency, respectively. Planting and inoculation were performed on June 9 in 1992, and sampling of these plants was performed on July 28. Values are means of 4 plants (two hills). Means in the same column followed by the same letter are not significantly different at the 5\% level by LSD.

Table 6. Nodule activity of field-grown soybeans inoculated with B. japonicum USDA110.

The occupation ratios of serogroup USDA110 in the nodules of the lateral roots were 53-67, 40-58, 63-83, and 62-77\% in the inoculated plants with the non- $R j^{-}, R j_{2}{ }^{-}, R j_{4^{-}}$and $R j_{2} R j_{3} R j_{4^{-}}$ genotypes, respectively. Therefore, these results indicated that infection by USDA110 occurred rapidly after the inoculation. $R j_{2} R j_{3} R j_{4^{-}}$genotypes suppress nodulation by the nodulation types $B$ and $C$ which are specific serogroups of the strains and they can select strains of nodulation type A to form nodules. As a result, they form nodules with only strains of the nodulation type A $[14,15]$. However, the $R j_{2} R j_{3} R j_{4}$-genotypes were not always nodulated by only USDA110 belonging to the nodulation type A. Soybean plants may possess a factor concerned with the preference for B. japonicum USDA110, except for these $R j$ genes. The mechanism of preference has not been elucidated, but it is assumed to relate to the increase in the population of the serogroup USDA110 in soils by the root activity. Also, 
Cregan and Keyser [24] screened out PI genotypes which excluded the B. japonicum strain of serogroup 123 in favor of the inoculated strain, and they suggested that the trait identified in the PI genotypes could exert a beneficial effect on soybean productivity by excluding all or a part of the indigenous serogroup 123 population in favor of more effective strains of $B$. japonicum. Their concept involving the preference of soybean genotypes for rhizobial strains may indicate that the planting of soybean genotypes compatible with efficient rhizobial strains could increase nitrogen fixation and dry matter production, as well as soybean yield. The second sampling was performed to investigate the changes in the occupation ratio of serogroup USDA110 with the progression of growth. The values revealed that the occupation ratios of serogroup USDA110 decreased for all the genotypes compared with those at the first sampling (Table 7). The reduction of the occupation ratio of serogroup USDA110 from the 1st until the 2nd sampling was lowest (0.13-0.16) in the $R j_{2} R j_{3} R j_{4}$-genotypes, excluding B349, followed by the non- $R j$ - and $R j_{2} R j_{3}$-genotypes and highest (0.52-0.69) in the $R j_{4^{-}}$ genotypes, excluding Hill. Therefore, it was considered that the population of compatible rhizobia with host soybean plants increased in the rhizosphere with the progression of development and growth, based on the following experimental basis.

\begin{tabular}{|c|c|c|c|c|}
\hline \multirow{2}{*}{$\begin{array}{l}R j- \\
\text { genotype }\end{array}$} & \multirow{2}{*}{$\begin{array}{l}\text { Cultivar } \\
\text { and Line }\end{array}$} & \multicolumn{2}{|c|}{ Occupation ratio (\%) } & \multirow{2}{*}{ Reduction } \\
\hline & & 1st sampling & 2nd sampling & \\
\hline Non- $R j$ & Akisirome & $67^{\text {bcd }}$ & $35^{\text {hi }}$ & 0.48 \\
\hline Non- $R j$ & Bragg & $53^{\mathrm{fg}}$ & 32 hi & 0.40 \\
\hline$R j_{2} R j_{3}$ & IAC-2 & $58^{\mathrm{c}}$ & $33^{\text {hi }}$ & 0.43 \\
\hline$R j_{2} R j_{3}$ & Hardee & $40 \mathrm{ghi}$ & $32 \mathrm{hi}$ & 0.20 \\
\hline$R j_{4}$ & Hill & $83^{\mathrm{a}}$ & $56^{\mathrm{c}}$ & 0.33 \\
\hline$R j_{4}$ & Fukuyutaka & $83^{\text {a }}$ & $26^{i}$ & 0.69 \\
\hline$R j_{4}$ & Akisengoku & 63 cde & $30^{\text {hi }}$ & 0.52 \\
\hline$R j_{2} R j_{3} R j_{4}$ & B340 & $74^{a b c}$ & $41 \mathrm{fgh}$ & 0.45 \\
\hline$R j_{2} R j_{3} R j_{4}$ & B349 & 62 de & 54 ef & 0.13 \\
\hline$R j_{2} R j_{3} R j_{4}$ & $\mathrm{C} 242$ & $77^{\text {ab }}$ & $65^{\text {bede }}$ & 0.16 \\
\hline
\end{tabular}

First sampling and second sampling conducted on July 28 and September 2, respectively. The same small letters next to each symbol are not significantly different at the $5 \%$ level by $X^{2}$ test. Reduction $=1$ - [Occupation ratio of the nodules on the lateral root at the vegetative stage] / [Occupation ratio of the nodules on the lateral root at the reproductive stage].

Table 7. Changes in the occupation ratio of $B$. japonicum belonging to serogroup USDA110 in the nodules on the lateral roots of field-grown soybeans with the progression of growth.

As a result, it was considered that in the rhizosphere of the $R j_{2} R j_{3} R j_{4}$-genotypes, the growth of the type A rhizobia was enhanced, while that of the types B and C rhizobia was repressed. Therefore, with the expansion of the root area of the host plant, the occupation ratio of the type A rhizobia including the serogroup USDA110 was high. Consequently, the $R j_{2} R j_{3} R j_{4}$-genotypes were considered to be superior to other $R j$-genotypes in terms of the inoculation effects of the nodulation type A of B. japonicum USDA110. However, it was estimated that the $R j_{2} R j_{3} R j_{4}$-genotypes were not always nodulated by only USDA110 belonging to the nodulation type A. The mechanism of preference of the $R j_{2} R j_{3} R j_{4}$-genotypes for the USDA110 serogroup has not been elucidated. 
The findings in this experiment on nodulation and RE, and the results of the serological tests, indicate that the $R j_{2} R j_{3} R j_{4}$-genotypes of soybean are superior to the non- $R j^{-}, R j_{2} R j_{3}$ - and $R j_{4}$-genotypes because they prefer rhizobial strains of serogroup USDA110 which are more active and form more efficient nodules in nitrogen fixation, compared with the other genotypes and because they are able to restrict nodulation with certain indigenous rhizobia. However, the preference of the $R j_{2} R j_{3} R j_{4}$-genotypes for serogroup USDA110 is not sufficient to rule out the competition with other serogroups. Therefore, the study should be focused on the isolation of efficient $\left(\mathrm{Hup}^{+}\right)$and highly compatible rhizobial strains with $R j_{2} R j_{3} R j_{4^{-}}$ genotypes. Also, the breeding of new $R j_{2} R j_{3} R j_{4}$-genotypes of soybean might be considered using both CNS $\left(R j_{2} R j_{3}\right)$ and Hill $\left(R j_{4}\right)$ cultivars in which the occupation ratio was found to be high by the inoculation of B. japonicum USDA110 (Table 7).

\section{Effect of $R j$ genotype and cultivation temperature on the community structure of soybean-nodulating bradyrhizobia}

Saeki et al. [25] investigated the genetic diversity and geographical distribution of indigenous bradyrhizobia isolated from five sites in Japan (Hokkaido, Fukushima, Kyoto, Miyazaki, Okinawa) by PCR restriction fragment length polymorphism (PCR-RFLP) analysis of the 16S-23S rRNA gene internal transcribed spacer (ITS) region and revealed that geographical distribution of indigenous bradyrhizobia varied from the northern to southern regions in Japan. As a result, the representative clusters of isolated indigenous bradyrhizobia were in the order of Bradyrhizobium japonicum USDA123, 110, and 6 and Bradyrhizobium elkanii USDA 76 ${ }^{\mathrm{T}}$ clusters from northern to southern regions in Japan. It has been suggested that an environmental factor such as temperature will influence the localization of Japanese indigenous bradyrhizobia. Saeki et al. [26] investigated the occupancy of three Bradyrhizobium japonicum strains and one Bradyrhizobium elkanii strain under different temperature conditions in soil and liquid media and suggested that temperature is one of the environmental factors that affect the occupancy of indigenous bradyrhizobia in soil.

Minami et al. [27] isolated 260 indigenous bradyrhizobia from 13 soybean cultivars of five $R j$-genotypes (non- $R j, R j_{2} R j_{3}, R j_{3}, R j_{4}$, and $R j_{2} R j_{3} R j_{4}$ ) from an Andosol and estimated the nodulation tendency among $R j$-genotype soybeans. The results showed that indigenous bradyrhizobial communities among the same Rj-genotype soybean cultivars were similar to each other, whereas indigenous bradyrhizobial communities between the $R j_{2} R j_{3}$-genotype and non- $R j^{-}, R j_{3}$-, or $R j_{4}$-genotype soybean cultivars were significantly different. However, They couldn't investigate the nodulation tendency by indigenous bradyrhizobia under different temperature conditions.

In the present section, to examine the influence of combinations of several cultivation temperatures and Rj-genotype soybean cultivars on the nodulation tendency and community structure of indigenous bradyrhizobia, we isolated indigenous bradyrhizobia from an Andosol using soybean cultivars of different $R j$-genotypes and several cultivation temperatures. The isolates were analyzed by PCR-RFLP of the 16S-23S rRNA gene ITS region, and a 
dendrogram was constructed to classify the isolates into clusters. The effects of cultivation temperature and $R j$-genotype on soybean-nodulating bradyrhizobial communities were also estimated.

\subsection{Materials and methods}

Soybean cultivars and soil samples: We used 13 soybean cultivars of four Rj-genotypes to investigate the effect of several cultivation temperatures and $R j$-genotypes of host soybean cultivars. The soybean cultivars were Akishirome, Bragg and Orhihime as non-Rj-genotypes, Bonminori, CNS, Hardee and IAC-2 as $R j_{2} R j_{3}$-genotypes, Akisengoku, Fukuyutaka and Hill as $R j_{4}$-genotypes, and A-250-3, B349 and C242 as $R j_{2} R j_{3} R j_{4}$-genotypes [14, 15]. As the soil sample, an Andosol ( $\mathrm{pH}\left[\mathrm{H}_{2} \mathrm{O}\right] 5.04$, electrical conductivity [EC] $=0.05 \mathrm{dS} \mathrm{m}^{-1}$; The National Agricultural Research Center for the Tohoku Region, Arai, Fukushima, Japan [25, 27]) was used for soybean cultivation because a high diversity of indigenous bradyrhizobia has been found in this soil in previous studies [25, 28].

Soybean cultivation: To isolate indigenous bradyrhizobia, we grew soybean cultivars in 1liter culture pots for 4 weeks. The culture pots were filled with vermiculite with $\mathrm{N}$-free nutrient solution [29] at $40 \%$ (vol/vol) water content and then autoclaved at $121^{\circ} \mathrm{C}$ for $20 \mathrm{~min}$. Soybean seeds were sterilized by soaking them in $70 \%$ ethanol for $30 \mathrm{~s}$ and in a dilute sodium hypochlorite solution $(0.25 \%$ available chlorine) for $3 \mathrm{~min}$ and then washing them with sterile distilled water. A soil sample ( 2 to $3 \mathrm{~g}$ ) was placed in the vermiculite at a depth of 2 to $3 \mathrm{~cm}$, and the soybean seeds were sown on the soil. The plants were grown for 4 weeks in a growth chamber (low: day, $23^{\circ} \mathrm{C}$ for $16 \mathrm{~h}$, and night, $18^{\circ} \mathrm{C}$ for $8 \mathrm{~h}$; middle: day, $28^{\circ} \mathrm{C}$ for $16 \mathrm{~h}$, and night, $23^{\circ} \mathrm{C}$ for $8 \mathrm{~h}$; and high: day, $33^{\circ} \mathrm{C}$ for $16 \mathrm{~h}$, and night, $28^{\circ} \mathrm{C}$ for $8 \mathrm{~h}$ ) with a weekly supply of sterile distilled water. After cultivating, 20 nodules were randomly collected from among all of the nodules harvested from soybean roots and sterilized by soaking them in $70 \%$ ethanol for $3 \mathrm{~min}$ and in a diluted sodium hypochlorite solution $(0.25 \%$ available chlorine) for $30 \mathrm{~min}$ and then washing them with sterile distilled water.

DNA samples of indigenous bradyrhizobia: Total DNA for the PCR template was extracted from a nodule directly as described by Hiraishi et al. [30] with slight modifications [29]. Each nodule was homogenized in $50 \mu \mathrm{L}$ of BL buffer ( $40 \mathrm{mM}$ Tris- $\mathrm{HCl}, 1 \%$ Tween $20,0.5 \%$ Nonidet P-40 and $1 \mathrm{mmol}$ of EDTA [pH 8.0]), $40 \mu \mathrm{l}$ of sterile distilled water, and $10 \mu \mathrm{L}$ of proteinase $\mathrm{K}\left(1 \mathrm{mg} \mathrm{mL}^{-1}\right)$ and then incubated at $60^{\circ} \mathrm{C}$ for $20 \mathrm{~min}$ and $95^{\circ} \mathrm{C}$ for $5 \mathrm{~min}$. After centrifugation, the supernatant was collected and used as the PCR template. A total of 780 DNA samples were obtained for further analysis.

PCR-RFLP analysis of the 16S-23S rRNA gene ITS region: As reference strains, total DNA for PCR template of strains B. japonicum USDA4, $6^{\mathrm{T}}, 38,110,115,123,124$, and 135 and B. elkanii USDA46, $76^{\mathrm{T}}$ and 94 [19] was prepared as described previously [31]. PCR was carried out using Ex Taq DNA polymerase (TaKaRa Bio, Otsu, Japan). For ITS amplification, we used the ITS primer set BraITS-F (5'-GACTGGGGTGAAGTCGTAAC-3') and BraITS-R (5'ACGTCCTT CATCGCCTC-3') [25]. The PCR cycle consisted of a pre-run at $94^{\circ} \mathrm{C}$ for $5 \mathrm{~min}$, denaturation at $94^{\circ} \mathrm{C}$ for $30 \mathrm{~s}$, annealing at $55^{\circ} \mathrm{C}$ for $30 \mathrm{~s}$, and extension at $72^{\circ} \mathrm{C}$ for $1 \mathrm{~min}$. This temperature control sequence was repeated for a total of 30 cycles and was followed by 
a final post-run at $72^{\circ} \mathrm{C}$ for $10 \mathrm{~min}$. The RFLP analysis of the 16S-23S rRNA gene ITS region was investigated using restriction enzymes HaeIII, HhaI, MspI, and XspI (Ta- KaRa Bio) [31]. A $5 \mu \mathrm{L}$ aliquot of the PCR product was digested with restriction enzyme at $37^{\circ} \mathrm{C}$ for $16 \mathrm{~h}$ in a $20 \mu \mathrm{L}$ reaction mixture. The restricted fragments were separated by agarose gel electrophoresis and visualized with ethidium bromide.

Cluster analysis: For the cluster analysis, we calculated the genetic distance between pairs of isolates (D). D was calculated from $N_{\mathrm{AB}}$ (the number of RFLP bands shared by the two strains) and $N_{\mathrm{A}}$ and $N_{\mathrm{B}}$ (the numbers of RFLP bands in strains A and B, respectively) [32, 33]. The cluster analysis was carried out using the unweighted pair group method with arithmetic average (UPGMA) method. The dendrograms were constructed using the PHYLIP software program v3.69 (J. Felsenstein, University of Washington, Seattle, WA).

Diversity analysis of bradyrhizobial communities: To estimate the diversity of the bradyrhizobial communities isolated from the host soybean cultivars, we used the Shannon-Wiener diversity index $[28,34,35]$. The formula for the diversity index was

$H^{\prime}=-\Sigma P i I n P i$

where $P i$ is the dominance of the isolates expressed by $n i / N, N$ is the total number of tested isolates $(n=20)$, and $n i$ is the total number of tested isolates belonging to a particular dendrogram cluster. The indexes of alpha diversity $\left(H^{\prime} \alpha\right)$, beta diversity $\left(H^{\prime} \beta\right)$, and gamma diversity $\left(H^{\prime} \gamma\right)$ were calculated $[36,37]$. These diversity indices were used to estimate the differences in the bradyrhizobial communities between cultivation temperature pairs. The $H^{\prime} \alpha$ index represents a weighted average of the diversity indices of each of the two bradyrhizobial communities, the $H^{\prime} \beta$ index represents the differences between the two bradyrhizobial communities from the two host soybean cultivars and the $H^{\prime} \gamma$ index represents the diversity of the total isolate communities from the two host soybean cultivars $(n=40)$. The relationship among these indices is

$H^{\prime} \beta=H^{\prime} \gamma-H^{\prime} \alpha$

We also estimated the differences among the compositions of the bradyrhizobial communities by comparing the ratio of the beta to the gamma index $\left(H^{\prime} \beta / H^{\prime} \gamma\right)$, taking into consideration the difference in gamma diversity in each pairwise comparison of bradyrhizobial communities.

\subsection{Results and discussion}

The PCR products of amplified 16S-23S rRNA gene ITS region were digested by four restriction enzymes, and the restriction fragments were separated by electrophoresis. The fragment sizes were estimated using a 50-bp ladder marker. A total of 36 operational taxonomic units (OTUs) containing 11 reference strains were detected [38]. The dendrogram was generated using the differences in fragment size and pattern. The maximum similarity among OTUs of the reference strains was $86 \%$ and occurred between B. japonicum USDA 38 and 115 . These results were then applied as the criterion for distinguishing clusters in the dendrogram, which produced 11 clusters, each of which contained 11 reference strains. The indigenous bradyrhizobia isolates in the 
middle and high cultivation temperatures were classified into seven clusters, Bj6, Bj38, Bj110, Bj115, Bj123, Be76, and Be94, while the indigenous bradyrhizobia isolates in the low cultivation temperature were classified into five clusters, Bj6, Bj38, Bj110, Bj115, and Bj123 [38]. For the low and middle cultivation temperatures, most of the indigenous bradyrhizobia were classified into four major clusters, Bj6, Bj38, Bj110, and Bj123, while most of the indigenous bradyrhizobia in the high cultivation temperature were classified into five major clusters, Bj6, Bj38, Bj110, Be76, and $\mathrm{Be} 94$. The indigenous bradyrhizobia belonging to the $\mathrm{Bj} 123$ cluster was not a major cluster at the high cultivation temperature.

Cluster analysis provided us with information about the cluster occupancy of each Rj-genotype and cultivation temperature. The occupancy rate of the Bj6, Bj38, Bj110, Bj115, Bj123, Be76, and Be94 clusters on the non- $R j^{-}, R j_{2} R j_{3}{ }^{-}, R j_{4^{-}}$, and $R j_{2} R j_{3} R j_{4}$-genotype soybean cultivars is shown in Table 8. Interestingly, the occupancy rate of Bj123 cluster was significantly decreased with increasing cultivation temperature. On the other hand, the occupancy rate of Bj110 cluster tended to increase with increasing cultivation temperatures. The Be76 and Be94 clusters had the same tendency as Bj110 cluster, but their occupancy rates were lower than that of Bj110 cluster (Table 8).

\section{Diversity analysis of the bradyrhizobial communities at various cultivation temperatures:} The differences in bradyrhizobial communities among the cultivation temperatures of each $R j$-genotype were also estimated by the $H^{\prime} \beta / H^{\prime} \gamma$ ratios. There was no significant difference (Tukey-Kramer test) based on the cultivation temperature in each Rj-genotype due to the variation of bradyrhizobial communities among each $R j$-genotype soybean cultivars was large, but the values of $H^{\prime} \beta / H^{\prime} \gamma$ between low and high cultivation temperature pairs tended to be higher than those of other cultivation temperature pairs (Fig. 1). In addition, the values of $H^{\prime} \beta / H^{\prime} \gamma$ of $R j_{2} R j_{3}$ - and $R j_{2} R j_{3} R j_{4}$-genotype soybean cultivars between low and high cultivation temperature pairs tended to be lower than the values of non- $R j$ - and $R j_{4}$-genotype soybean cultivars (Fig. 1). The values of $H^{\prime} \beta / H^{\prime} \gamma$ of $R j_{2} R j_{3} R j_{4}$-genotype soybean cultivars, tended to be comparatively lower than those of non- $R j$ - and $R j_{4}$-genotype soybean cultivars and were similar to the values of $H^{\prime} \beta / H^{\prime} \gamma$ of $R j_{2} R j_{3}$-genotype soybean cultivars.

With increasing cultivation temperature from low to high, the occupancy rate of the Bj123 cluster decreased and the occupancy rate of the Bj110 cluster increased. Furthermore, the soybean cultivars with $R j_{2} R j_{3}$-genotypes and $R j_{2} R j_{3} R j_{4}$-genotypes showed a higher occupancy rate of the Bj110 cluster (50-73.8\%) than other $R j$-genotype soybean cultivars (Table 8 ), suggesting that the host soybean $R j$-genotype affected the infection of some specific bradyrhizobia. Yamakawa et al. [23] reported that $R j_{2} R j_{3} R j_{4}$ - genotype cultivars were superior to other $R j$-genotypes for inoculation with B. japonicum USDA110. In the present study, we did not demonstrate the inoculum efficiency of B. japonicum USDA110; however, this previous result suggested that $R j_{2} R j_{3}$ - and $R j_{2} R j_{3} R j_{4}$ - genotype soybean cultivars may enhance the occupancy rate of the inoculum of $B$. japonicum USDA110. In addition, the occupancy rate of the Bj110 cluster in $R j_{2} R j_{3} R j_{4}$-genotypes did not show significant differences among the three cultivation temperature conditions tested (Table 8 ), suggesting that $R j_{2} R j_{3} R j_{4}$-genotype soybean cultivars were unaffected by cultivation temperature changes and may enhance the inoculum efficiency such as that of B. japonicum USDA110. 


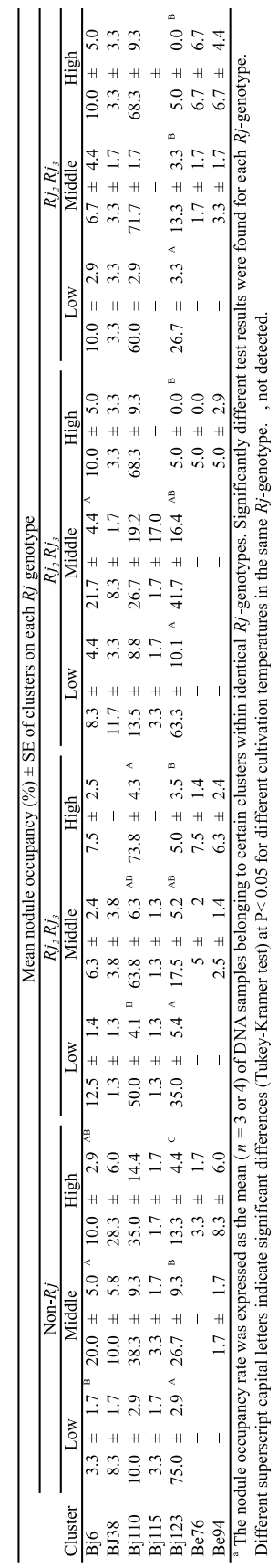

Table 8. Nodule occupancy rate of soybean-nodulating bradyrhizobia for cluster analysisa. 


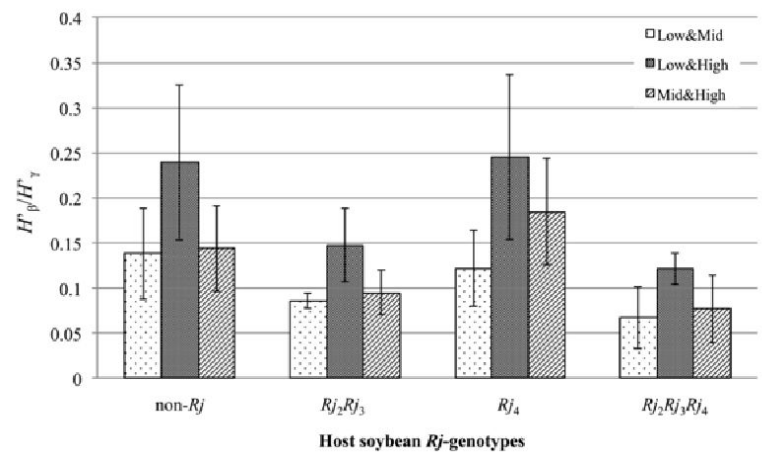

Figure 1. Difference in beta diversity compared to gamma diversity $\left(H^{\prime} \beta / H^{\prime} \gamma\right)$ among pairs of cultivation temperatures. Each value is expressed as the mean \pm the standard error $(n=3$ or 4$]$.

We also investigated the differences in bradyrhizobial communities for the pairs of cultivation temperature. The nodulation tendencies of soybean cultivars were similar for each cultivation temperature, and differences in the community structures between low and high cultivation temperatures were relatively larger than the other comparisons, although the statistical significant difference was not detected. This possible reason is that responses of soybean cultivars for cultivation temperatures on soybean nodulating bradyrhizobial communities are different among each soybean cultivar even in same Rj-genotypes. Therefore, analyses of soybean-nodulating rhizobial communities on not only Rj-genotypes but also every soybean cultivars must be conducted for environmental factors affecting soybean-nodulating rhizobial community structures such as cultivation temperature in further studies. The responses of host soybean and soybean-nodulating bradyrhizobia under cultivation conditions such as a suboptimal root zone temperature were reported previously. The lowering of temperature delayed bradyrhizobia infection of soybean roots and lowered the genistein secretion from soybean roots $[39,40]$. It also appeared to inhibit the expression of the nodulation (nod) gene of soybean-nodulating bradyrhizobia [41]. However, Pan and Smith [42] reported that the concentration of daidzein secreted from soybean roots increased with decreasing root zone temperature. The physiological factors of bradyrhizobia involved in the nodulation are the expression of the nod gene and growth capability in soil and rhizosphere. Yokoyama [43] demonstrated that the expression level of the nod gene of three Bradyrhizobium strains, B. japonicum USDA110 strain, B. elkanii USDA76 strain, and Bradyrhizobium sp. TARC 64 strain (isolates from Thailand soil [44]), which were mutants of nod $Y$-lacZ fusion, were different depending on the incubation temperature $(20,23,26,30,33$, 35,37 , and $40^{\circ} \mathrm{C}$ ) and suggested that the transcriptional responses of the nod gene of USDA110 strain and USDA76 strain were distinctly different at 23 to $35^{\circ} \mathrm{C}$. Saeki et al. [28] demonstrated that the population occupancy of four Bradyrhizobium USDA strains, B. japonicum USDA6 ${ }^{\mathrm{T}}, 38$, and 123 and B. elkanii USDA76 ${ }^{\mathrm{T}}$, in soil microcosms changed with different 
temperature conditions and indicated that USDA76 ${ }^{\mathrm{T}}$ was dominant over a wide range of temperature conditions, especially at higher temperature, whereas USDA123 was dominant at low soil temperatures. These results suggested that temperature is one of the environmental factors affecting the infection of soybean and the bradyrhizobia occupancy in soils. Furthermore, Duzan et al. [45] reported that the deformations of soybean root hair decreased with decreasing root zone temperature. The infection and nodulation of soybean by bradyrhizobia under different temperature conditions may be affected by other, as-yet-unknown factors as well.

\section{5. $R j$-gene specific nodulation genes (Rj-gsn genes) of Bradyrhizobium strains}

Genotype-specific nodulation $(g s n)$ genes are reported in B. japonicum. The nolA gene allowed serogroup 123 strains to nodulate soybean plants having USDA123 restricting Plant Introduction (PI) genotypes [46]. The noeD gene restricted nodulation of soybean genotype PI 417566 with USDA110 [47]. There have been, however, no reports of the identification of the Rj-genotype specific nodulation (Rj-gsn) gene that is related to the incompatible combinations with $R j$ soybeans. This study reports the isolation and characterization of Tn 5 mutants of $B$. japonicum strain Is- 1 with the ability to nodulate cv. CNS $\left(R j_{2} R j_{3}\right)$ and shows the candidates of the $R j$-gsn genes with the identifications of Tn5-flanking sequences in these mutants. As this is the first report to overcome the nodulation restriction conditioned by $R j_{2}{ }^{-}$ cultivars, these mutants will be helpful in identifying the Rj-gsn gene in further studies.

\subsection{Materials and methods}

Plants: Soybean (Glycine max L. Merr.) cvs. CNS $\left(R j_{2} R j_{3}\right)$, D- $51\left(R j_{3}\right)$, Hardee $\left(R j_{2} R j_{3}\right)$, Hill $\left(R j_{4}\right)$ and IAC-2 $\left(R j_{2} R j_{3}\right)$ were used. No soybean cultivar harboring only the $R j_{2}$-gene has been reported to date. The $R j$-genotypes are indicated in parentheses [11, 14].

Bacterial strains and plasmids: The bacterial strains and plasmids used in this study are described in Table 9. The B. japonicum strain Is-1 [13] and Tn5 mutants were grown on HM salt medium [48] supplemented with $0.1 \%$ arabinose at $30^{\circ} \mathrm{C}$. Escherichia coli strains were grown on Luria-Bertani medium [49] at $37^{\circ} \mathrm{C}$. Antibiotics were added to the media at the following final concentrations: kanamycin at $50 \mu \mathrm{g} \mathrm{mL}-1$ for Tn5 mutant and ampicillin at $100 \mu \mathrm{g} \mathrm{mL}-1$ and kanamycin at $50 \mu \mathrm{g} \mathrm{mL} \mathrm{m}^{-1}$ for E. coli S17-1 harboring pUTKm (Table 9).

Tn5 mutagenesis: Transposon mini-Tn 5 was introduced into B. japonicum strain Is- 1 by mating with E. coli strain S17-1 [50] carrying the suicide vector pUTKm [51]. The E. coli donor strain S17-1 (pUTKm) was grown with kanamycin and ampicillin for $12 \mathrm{~h}$ at $100 \mathrm{rpm}$ in a rotatory shaker, and then $1 \mathrm{~mL}$ of culture was spun down for $2 \mathrm{~min}$ at $4,000 \times \mathrm{g}$, and then rinsed three times with HM salts medium [52] to remove the antibiotics, and then suspended into $50 \mu \mathrm{L}$ of HM salts medium. The B. japonicum strain Is- 1 was grown for 6 days at 100 $\mathrm{rpm}$ in a rotatory shaker, and then $2 \mathrm{~mL}$ of the culture was spun down for $3 \mathrm{~min}$ at $9,000 \times \mathrm{g}$ 
and then suspended into $50 \mu \mathrm{L}$ of HM salt medium. Equal volumes $(50 \mu \mathrm{L})$ of $E$. coli donor and B. japonicum recipient cells prepared as described above were mixed in a $1.5-\mathrm{mL}$ eppendorf tube. The mating mixture was spread onto a cellulose acetate membrane filter (Advantec, Tokyo, Japan; pore size $0.45 \mu \mathrm{m}$ ). The mating was carried out on $\mathrm{HM}$ plates at $30^{\circ} \mathrm{C}$. The incubation time of the mating was 2 days. After mating, cells were suspended in $1 \mathrm{~mL}$ of $\mathrm{HM}$ salts medium and $100 \mu \mathrm{L}$ aliquots of this suspension were spread onto $10 \mathrm{HM}$ plates. Kanamycin was added to select for kanamycine-resistant $\left(\mathrm{Km}^{\mathrm{r}}\right)$ transconjugants.

\begin{tabular}{|c|c|c|}
\hline Strain and plasmid & Relevant chracteristics & Reference or source \\
\hline \multicolumn{3}{|c|}{ Bradyrhizobium japonicum } \\
\hline Is-1 & Incompatible with $R j 2 R j 3$ soybean and compatible with $R j 4$ & Ishizuka et al. (1991a) \\
\hline 1C1 & Is-1::Tn5, $\mathrm{Km}^{\mathrm{r}}$ & This study \\
\hline 1C2 & Is-1::Tn5, $\mathrm{Km}^{\mathrm{r}}$ & This study \\
\hline $5 \mathrm{C} 1$ & Is- $1:: \operatorname{Tn} 5, \mathrm{Km}^{\mathrm{r}}$ & This study \\
\hline $6 C 1$ & Is- $1:: \operatorname{Tn} 5, \mathrm{Km}^{\mathrm{r}}$ & This study \\
\hline 7C1 & Is- $1:: \operatorname{Tn} 5, \mathrm{Km}^{\mathrm{r}}$ & This study \\
\hline 7C2 & Is- $1:: \operatorname{Tn} 5, \mathrm{Km}^{\mathrm{r}}$ & This study \\
\hline $10 \mathrm{C} 1$ & Tn5-induced spontaneous mutant, $\mathrm{Km}^{\mathrm{r}}$ & This study \\
\hline $10 \mathrm{C} 2$ & Is- $1:: \operatorname{Tn} 5, \mathrm{Km}^{\mathrm{r}}$ & This study \\
\hline \multicolumn{3}{|l|}{ Escherichia coli } \\
\hline S17-1 & pro thi recA hsdR; chromosomal RP4-2(Tnl::ISRI tet::Mu Km::Tn7) & Simon et al. (1983) \\
\hline JM109 & recA1; cloning strain & Takara Bio, Shiga, Japan \\
\hline \multicolumn{3}{|l|}{ Plasmid } \\
\hline pUTKm & Tn5-based delivery plasmid with $\mathrm{Km}^{\mathrm{r}}, \mathrm{Ap}^{\mathrm{r}}$ & Herrero et al. 1990 \\
\hline
\end{tabular}

Km, kanamycin; Amp, ampicillin.

Table 9. Bacterial strains and plasmids used in this study.

Isolation of Tn5 mutants: All $\mathrm{Km}^{\mathrm{r}}$ transconjugant colonies in each $\mathrm{HM}$ plate were suspended in $20 \mathrm{~mL}$ of $\mathrm{HM}$ medium and cultivated for 7 days at $30^{\circ} \mathrm{C}$. These 10 cultures containing $\mathrm{Km}^{\mathrm{r}}$ transconjugants were separately spun down for $10 \mathrm{~min}$ at 6,000 $\times \mathrm{g}$ and then rinsed twice with half-strength modified Hoagland nutrient (MHN) solution [53] to remove the antibiotic. Each pellet of $\mathrm{Km}^{\mathrm{r}}$ transconjugants was suspended in $60 \mathrm{~mL}$ of MHN solution. These 10 suspensions were separately inoculated onto CNS $\left(R j_{2} R j_{3}\right)$ at a rate of $5 \mathrm{~mL}$ per seed in each pot. The pots and seeds were prepared as follows. Both vermiculite $(2.8 \mathrm{~L})$ and MHN solution $(1.4 \mathrm{~L})$ were added to a 3.0-L porcelain pot and autoclaved at $121^{\circ} \mathrm{C}$ for 20 min. The seeds were sterilized with $5 \%$ sodium hypochlorite for $5 \mathrm{~min}$ and then rinsed with ethanol five times, and then rinsed with MHN solution five times. The surface-sterilized seeds of CNS were planted in a vermiculite medium at a rate of 12 seeds per pot. The inoculated plants were grown in a phytotron controlled at $25 \pm 1^{\circ} \mathrm{C}$ under natural light conditions and sterilized water was supplied to maintain the moisture content. After 4 weeks of cultivation, Tn5 mutants were isolated from nodules produced on the root of CNS. The nodules were washed to remove vermiculite and immersed in $95 \%$ ethanol for $1 \mathrm{~min}$, and then in $5 \%$ hydrogen peroxide solution for $5 \mathrm{~min}$. The sterilized nodule was crushed and suspended in $5 \mathrm{~mL}$ of autoclaved $0.9 \%$ saline water. A drop of the turbid suspension was transferred to a yeast extract mannitol agar (YMA) plate [16] containing Congo Red (25 $\left.\mu \mathrm{g} \mathrm{mL} \mathrm{m}^{-1}\right)$ and streaked. These plates were incubated for 7 days at $30^{\circ} \mathrm{C}$. 
Amplification of the Tn5-flanking sequence: Kwon and Ricke [54] developed an efficient method to specifically amplify the transposon-flanking sequences with unique Y-shape linkers. The amplification of Tn5- flanking sequence was carried out according to their method. Because pUTKm was used to carry out Tn5 mutagenesis in both our study and the study by Kwon and Ricke [54], the same oligonucleotides are used in these two experiments: Linker 1, 5'- TTTCTGCTCGAATTCAAGCTTCTAACGATGTACGGGGACACATG-3'; Linker 2, 5' TGTCCCCGTACATCGTTAGAACTACTCGTACCATCCACAT-3'; Y linker primer, $5^{\prime}$ CTGCTCGAATTCAAGCTTCT-3'; Tn5 primer, 5' - GGCCAGATCTGATCAAGAGA-3'. The genomic DNA was prepared using ISOPLANT (Nippon gene, Toyama, Japan). The Y linker was designed to have a $3^{\prime}$ overhang complementary to the sticky end generated by the Nla III or Sph I. In the present study, Sph I (Toyobo, Osaka, Japan) was used for digestion of the genomic DNA. Polymerase chain reactions (PCR) were carried out using the Program Temp Control System (ASTEC, Fukuoka, Japan) and TaKaRa Ex Taq Hot Start Version (Takara Bio, Shiga, Japan). Thermal cycling conditions were as follows: initial denaturing was carried out for $2 \mathrm{~min}$ at $95^{\circ} \mathrm{C}$ followed by 30 cycles of denaturing $\left(30 \mathrm{~s}\right.$ at $\left.95^{\circ} \mathrm{C}\right)$, annealing $(30 \mathrm{~s}$ at $60^{\circ} \mathrm{C}$ ) and extension $\left(90 \mathrm{~s}\right.$ at $\left.70^{\circ} \mathrm{C}\right)$. After the final cycle an extension step of $5 \mathrm{~min}$ at $70^{\circ} \mathrm{C}$ was added. The PCR products were analyzed on a 3\% agarose gel (Nacalai Tesque, Kyoto, Japan) and stained with ethidium bromide (Nacalai Tesque, Kyoto, Japan).

Cloning, DNA sequencing and sequence analysis: The PCR products were cloned with pGEM-T Easy Vector System (Promega, Madison, WI, USA) (Table 9). Cloned DNA fragments were sequenced commercially by Macrogen (Seoul, Korea). Homology searches were carried out using the BLASTN program in the RhizoBase, which is a database for the genome of B. japonicum USDA110 (http://www.kazusa.or.jp/rhizobase/Bradyrhizobium/).

\subsection{Results and discussion}

Eight nodules and two popcorn-like nodules were produced on cv. CNS $\left(\mathrm{Rj}_{2} R j_{3}\right)$ inoculated with the $\mathrm{Km}^{\mathrm{r}}$ transconjugants. Tn5 mutants $(1 \mathrm{C} 1,1 \mathrm{C} 2,5 \mathrm{C} 1,6 \mathrm{C} 1,7 \mathrm{C} 1,7 \mathrm{C} 2,10 \mathrm{C} 1$ and 10C2) were isolated from the eight nodules and no Tn5 mutants were isolated from the popcornlike nodules. The nodulation type [13] of Tn5 mutants was determined with $\mathrm{CNS}\left(R j_{2} R j_{3}\right)$ and Hill $\left(R j_{4}\right)$. All of them nodulated CNS effectively and retained the ability to nodulate Hill effectively [55]. Nodule effectiveness was judged by whether or not the nodule section indicated a section of red color. All Tn5 mutants were classified into nodulation type A. Although all nodules formed by Tn5 mutants indicated a red color section, the nitrogen fixation activities were different for each one. In particular, the nitrogen fixation activities of $6 \mathrm{C} 1$ and 7C1 were drastically low. The nodulation profile test was carried out with D-51 $\left(R j_{3}\right)$, Hardee $\left(R j_{2} R j_{3}\right)$ and IAC-2 $\left(R j_{2} R j_{3}\right)$. All Tn5 mutants nodulated both the $R j_{2} R j_{3}$ - and the $R j_{3}-$ cultivars effectively.

The results of the electrophoresis of the PCR products showed that all mutants except for $10 \mathrm{C} 1$ contained a single copy of Tn5 and that the fragment size of each PCR product was different. The PCR product amplified from 10C1 was not detected [55]. These results are equal to those obtained by genomic southern blot analysis (data not shown). 


\begin{tabular}{|c|c|c|c|c|c|}
\hline Tn5 mutant & Length & Identity & Location $^{\dagger}$ & Gene $^{\ddagger}$ & Deduced gene product \\
\hline $1 \mathrm{C} 1$ & 773 & 769/773(99\%) & $5009532-5010304 \mathrm{~b}$ & bll4521 & Probable rare lipoprotein $\mathrm{A}$ \\
\hline $1 \mathrm{C} 2^{\S}$ & 1484 & $1478 / 1484(99 \%)$ & $8203627-8205110$ b & bsr7468 & Cold shock protein \\
\hline $5 \mathrm{C} 1$ & 756 & $752 / 756(99 \%)$ & $1540572-1541327$ b & blr1414 & Transcriptional regulatory protein ArsR family \\
\hline $6 C 1$ & 227 & $227 / 227(100 \%)$ & 1308155-1307929 b & bll1193 & Integral inner membrane metabolite transport protein \\
\hline 7C1 & 1896 & $1892 / 1896(99 \%)$ & $6149473-6151368$ b & bll5593 & Unknown protein \\
\hline $7 \mathrm{C} 2$ & 2092 & 2070/2092(98\%) & 6353378-6355469 b & blr5786 & Putative integral membrane protein \\
\hline $10 \mathrm{C} 2$ & 2092 & 2070/2092(98\%) & 6353378-6355469 b & blr5786 & Putative integral membrane protein \\
\hline
\end{tabular}

Table 10. Results of the blast searches of Tn5-flanking sequences based on RhizoBase.

The results of blast searches of cloned PCR products against the RhizoBase revealed that all homologous sequences to Tn5-flanking sequences were found in the complete genome sequence of B. japonicum USDA110 [56] (Table 10). All of them were located in different regions in the genome of $B$. japonicum USDA110 and all of them except for one in mutant 1C2 are within the open reading frames predicted by the USDA110 genome sequence project (Table 10). Using the "plasmid rescue" method [57], we have already determined Tn5-flanking sequences longer than the ones found in this report [58]. These sequences have been deposited into the DNA Data Bank of Japan (DDBJ) database (sequential accession numbers AB243409 through to AB243415].

B. japonicum strain USDA110 has an ability to form root nodules on soybeans (Glycine max L. Merr.) and is superior at symbiotic nitrogen fixation with soybeans compared with other strains [2]. The complete genome sequence of this strain has been determined [56]. This sequence information is a useful tool to determine the mechanism of nodulation and nitrogen fixation in B. japonicum. The effect of rhizobial inoculation depends largely on the nitrogen fixation ability of the strain that forms most of the nodules. However, in soils containing indigenous bradyrhizobia, the inoculation of highly effective rhizobia does not always result in the formation of effective nodules and in high nitrogen fixation [59]. To improve the effectiveness of the inoculation, the molecular genetic information of various strains, as well as USDA110, is believed to be required. The B. japonicum strain Is-1 nodulated Hill $\left(R j_{4}\right)$ but did not nodulate CNS $\left(R_{2} R j_{3}\right)$ and was classified into the nodulation type B. Although the $g s n$ genes have been reported [46, 60], there have been no reports of the identification of an $R j$ gsn gene. In this study, Tn5 mutants were isolated from nodules produced on CNS inoculated with the $\mathrm{Km}^{\mathrm{r}}$ transconjugants. It is confirmed that these mutants are derived from Is-1 using amplified fragment length polymorphism (AFLP) analysis [61].

Tn5-flanking sequences were specifically amplified from Tn5 mutants except for 10C1 [58]. These results show that all mutants except for $10 \mathrm{C} 1$ contained a single copy of $\mathrm{Tn} 5$ and that each Tn5 insertion site was different and that $10 \mathrm{C} 1$ is probably a spontaneous kanamycinresistant mutant. Wei and Bauer [62] also reported that Tn5-induced mutants with different phenotypes from the wild strain did not contain Tn5 insertion. The analyses of these sequences showed that all Tn 5 mutants contained a single copy of Tn 5 and that each Tn 5 insertion site was different. There was no clear relationship among the Tn5-inserted gene products. However, most of the Tn5-inserted gene products related to the cell membrane structure 
(e.g. the probable rare lipoprotein A, cold shock protein, the transcriptional regulatory protein ArsR family, integral inner-membrane metabolite transport protein and putative integral membrane protein) (Table 10). The probable rare lipoprotein A, integral innermembrane metabolite transport protein and putative integral membrane protein are a part of the membrane structure. Meanwhile, it is thought that cold shock protein and the transcriptional regulatory protein ArsR family may be indirectly related to the membrane structure. The membrane-bound pump is regulated by the ArsR family [63] and the relationship between cold shock protein and membrane composition was reviewed by Ulusu et al. [64]. Therefore, changes or damage to the cell membrane structure in mutants may overcome the nodulation restriction conditioned by $R j_{2}$-soybean. Judd et al. [65], however, reported that the transposon was not responsible for host range extension in the Tn5 mutant of USDA 438. In the future, we must confirm that the Tn 5 insertion is responsible for the acquisition of the ability to nodulate $R j_{2}$-soybean.

\section{Inoculation techniques using compatibility between $R j$-genes and Bradyrhizobium strains}

In our laboratory, an experiment for testing effects of inoculation into a cylindrical soil block from just above the seed were conducted using bacterial suspension of Bradyrhizobium japonicum USDA110 as useful rhizobia in the past. The results showed that the occupation ratio of USDA110 in the tap roots was as high as $70-100 \%$ and that in the lateral root was $44-77 \%$ lower than that of tap root and decreased in progression of the growth and developing of the host plant. In particular, the extreme decrease of USDA110 occupation was observed in soybean variety Fukuyutakaa, which was cultivated as a recommended variety in the southwest warm region of Kyushu in Japan. It is likely that the cause of reduced occupancy in lateral roots occurred because rhizobia were inoculated in the narrow range around the tap root, while lateral roots continued to grow outside of the inoculation column. If the range of inoculation were enlarged, the occupancy ratio of lateral roots probably would have increased.

In 2005, a field experiment was conducted to clarify the effect of the difference on soybean production between the inoculation of rhizobia on the seed surface compared with the plow layer [66]. Non-inoculated plot (NI), seed coat inoculation (SI) plot, and plow layer rhizobial solution inoculation (RI) plots were tested in three replications. Rhizobial concentration for inoculation was $10^{7}$ cells/seed in both plots. As the result, the number of nodulation and the occupancy ratio of serotype USDA110 were highest in the SI plot, however yield $(\mathrm{kg} / 10 \mathrm{a})$ was higher in the RI plot versus other plots. This occurred is because the inoculum density in the SI plot was high, resulting in many nodules formed. This increased competition of photosynthetic products between the growth of soybean and nodulation, and consequently the initial growth was suppressed. For the SI plot, the effect of inoculation was expected to decline with time. In addition, since the occupancy ratio of inoculum was less than $50 \%$, it is considered likely that the yield would increase if the seed surface inoculation were high. 
Based on these results, it is important to examine the relationship between nodulation method and the effective inoculum concentration on the seed.

Therefore, the purpose of this study was to clarify the effect of the difference in inoculation method and inoculum density of B. japonicum USDA110 on soybean production.

\subsection{Materials and methods}

Soybean (Glycine max L. Merr.) variety Fukuyutak and B. japonicum USDA110 having uptake hydrogenase $\left(\mathrm{Hup}^{+}\right)$were used in this experiment. B. japonicum USDA110 was cultured in $\mathrm{HM}$ medium for eight days with shaking at $30^{\circ} \mathrm{C}$ used for inoculation. Fukuyutaka was cultivated in the farm of Kyushu University Faculty of Agriculture, where barley was grown as the previous crop and soybean had not been grown for the past five years. Experimental plots had three replications for the treatments: non-inoculation (NI) plot, seed coat inoculation (SI) plots; $10^{5}$ cells/seed (SI5) plot and $10^{7}$ cells/seed (SI7) plot, and plow layer rhizobial peat-moss inoculation (PI) plots; $10^{7}$ cells/seed (PI7) plot and $10^{9}$ cells/seed (PI9) plot. Peatmoss inoculation was conducted using mixture of BM2 (raw materials: peat-moss, Group Berger Peat Moss Ltd., Canada) USDA110 culture inoculated into the plow layer before seed sowing to be $10^{7}$ or $10^{9}$ cells/seed.

Inoculum for SI plot per 100 seeds was made from $1.5 \mathrm{~mL}$ deionized water and $10 \mathrm{ml}$ of $12 \%$ aqueous solution of gum arabic, $10 \mathrm{~g}$ of BM2 and $0.015 \mathrm{~mL}$ (SI5) or $1.5 \mathrm{~mL}$ (SI7) of USDA110 culture solution $\left(1 \times 10^{9}\right.$ cells $\left./ \mathrm{mL}\right)$. Inoculum for PI plot per $\mathrm{m}^{2}$ was mixed well BM2 of $200 \mathrm{~g}$ spread on the plastic sheet, tap water of $40 \%$ of the maximum water holding capacity of BM2 and USDA110 culture solution of $0.25 \mathrm{~mL}\left(10^{7}\right.$ cells/seed) or $25.0 \mathrm{~mL}\left(10^{9}\right.$ cells/seed). After spraying the mixture into the row of the test plot, the rows were plowed (approximately $15 \mathrm{~cm}$ depth) by a tractor. The amount of USDA110 in the plow layer after inoculation was $10^{7}$ or $10^{9}$ cells per $1,800 \mathrm{~cm}^{3}\left(60 \times 20 \times 15 \mathrm{~cm}^{3}\right)$ of soil occupying the root zone of one hill (three seeds sown). As a result, the inoculum density of USDA110 in the plow layer of each plot, PI9 and PI7 was estimated to be 1.7 $\times 10^{3}$ and $1.7 \times 10^{5}$ cells/g DW soil. The amount of lime carbonate for adjusting to 6.5 soil $\mathrm{pH}$ was estimated by the buffer curve method using soil samples collected from 6 points (15 cm soil depth) in the experimental field. After applying the lime carbonate, on July 11, Mame kasei (3.0\% ammonia nitrogen, $10.0 \%$ acid soluble phosphorus, $10.0 \%$ watersoluble potash) was applied at a rate of $80 \mathrm{~kg}$ per 10 a to all layers. Inoculation of the PI plot was done on July 18. On July 28, seeds of Fukuyutaka of all plots were sown into hills of either 20 or $60 \mathrm{~cm}$ apart, at a depth of approximately $2-3 \mathrm{~cm}$. The seedlings were thinned to two seedlings at the trifoliate stage (V2). At V5 stage, the inter row area was cultivated and ridged. Pesticides were sprayed according to the occurrence of insect pests. Plants of one hill per each plot were sampled for roots at V6.4 and R5.7 stage, and 10 hills were harvested by cutting the stem at R8 stage (November 2 or 8).

To estimate the density of indigenous rhizobia, soils were collected from two locations in the experimental field before fertilization and the rhizobia density was measured by the most probable number (MPN) method using soybean cultivars, Orihime (non-Rj-genotype) and Fukuyutaka ( $R j_{4}$-genotype). Plants sampled for roots at V6.4 and R5.7 stage [67] were divid- 
ed into shoots and roots. Roots were used for measurement of acetylene reduction activity (ARA) and counting of nodules. Counting of nodules was done after partitioning the plant into five parts the upper $3 \mathrm{~cm}$ of tap root, the lower part of the tap root, the lateral roots generated from the upper tap root, the lateral roots generated from the lower tap root and the superficial roots. Nodules from these samples were freeze-dried. Plant parts were airdried at $80^{\circ} \mathrm{C}$ for $24-48 \mathrm{hrs}$. Also, in order to determine the effect of inoculation, the freezedried nodules were evaluated with serological tests performed using USDA110 antiserum produced previously in our laboratory. USDA110 occupancy was analyzed by the $\chi^{2}$ test.

After examining individual harvest yield components (effective number of pods $/ \mathrm{m}^{2}$, seeds number/pods, complete seed percentage, one hundred seed weight $(\mathrm{g})$, yield $\left(\mathrm{g} / \mathrm{m}^{2}\right)$ in each plot), plant dry weight of plant part was weighed. For each growth stage, significant differences were determined according to LSD test (Fisher) after ANOVA analysis.

\subsection{Results and desucassion}

Occupation of useful rhizobium inoculated on the seed coat was known to be low because of their low competition against indigenous rhizobia. This object was to clarify the effect of inoculation method and inoculum density of B. japonicum USDA110 on production of soybean. Five experimental plots were designed:, no inoculation (NI), seed coating inoculation with a density of $10^{5}$ cells/seed (SI5) and $10^{7}$ cells/seed (SI7), previous inoculation into the root zone with a density of $1.7 \times 10^{3}$ cells/g soil (PI7) and $1.7 \times 10^{5}$ cells/g soil (PI9). The PI plots were plowed after the BM2 mixture was soaked with rhizobium culture.

\begin{tabular}{|c|c|c|c|c|c|c|c|}
\hline \multirow{2}{*}{$\begin{array}{l}\text { Growth } \\
\text { Stage }\end{array}$} & \multirow[t]{2}{*}{ Treatment } & \multirow{2}{*}{$\begin{array}{c}\text { Superficical } \\
\text { root }\end{array}$} & \multicolumn{2}{|c|}{ Tap root } & \multicolumn{2}{|c|}{ Lateral roots } & \multirow{2}{*}{ Total } \\
\hline & & & Upper & Lower & Upper & Lower & \\
\hline \multirow[t]{5}{*}{$\begin{array}{l}\text { V6.4 } \\
\end{array}$} & NI & 13.7 & 32.7 & 24.3 & $39.7 \mathrm{~b}$ & 13.7 & 124.0 \\
\hline & SI5 & 18.3 & 37.7 & 33.0 & $38.3 \mathrm{~b}$ & 16.3 & 143.7 \\
\hline & SI7 & 17.3 & 33.0 & 18.7 & $42.7 \mathrm{~b}$ & 27.7 & 139.3 \\
\hline & PI7 & 8.3 & 33.7 & 34.7 & 70.7ab & 25.3 & 160.7 \\
\hline & PI9 & 16.0 & 21.0 & 24.0 & 90.7 a & 18.3 & 170.0 \\
\hline \multirow[t]{5}{*}{ R5.7 } & NI & 47.7 & 46.7 & $28.0 \mathrm{a}$ & 214.3 & 35.3 & 372.0 \\
\hline & SI5 & 55.0 & 30.3 & $24.7 \mathrm{ab}$ & 167.0 & 27.7 & 304.7 \\
\hline & SI7 & 61.7 & 37.3 & $13.3 \mathrm{~b}$ & 211.3 & 34.0 & 357.7 \\
\hline & PI7 & 31.3 & 32.0 & $15.7 \mathrm{ab}$ & 237.7 & 25.3 & 342.0 \\
\hline & PI9 & 39.0 & 29.3 & 14.0ab & 183.3 & 27.0 & 292.7 \\
\hline
\end{tabular}

Mean followed by same and without letters within a column of each stage are not significantly different using LSD $(P<0.10)$.

Table 11. Transition of nodule number in each growth stage effected by inoculation methods.

Table 11 shows the effect of inoculation methods on nodulation efficiency. The PI treatment had high efficiency for the lateral roots at the V6.4 stage, but at R5.7, the efficiency was low. For all other root positions and inoculation methods, the efficiency was low. Occupation ratio of serotype USDA110 on the total root was significantly highest for SI7 and PI9 and lowest in PI7 at the V6.4 stage. At the R5.7 stage, the occupation ratio in the superficial and upper lateral roots increased especially by inoculation with the B. japonicum USDA110, ex- 
cept the superficial roots of PI7. Also, for whole roots, the occupation ratio was significantly increased by inoculation of B. japonicum USDA110, except for PI7 (Table 12). However, the ARA showed a tendency to decrease with high density inoculum (Table 13). These results were complemented by seed yields of Fukuyutaka being highest in SI5 and SI7 (Table 14).

\begin{tabular}{cccccccc}
\hline $\begin{array}{c}\text { Growth } \\
\text { Stage }\end{array}$ & Treatment & $\begin{array}{c}\text { Superficial } \\
\text { root }\end{array}$ & Upper & Lower & Upper & Lower & Total \\
\hline V6.4 & NI & 12.5 & $15.0 \mathrm{bc}$ & $25.0 \mathrm{ab}$ & $20.5 \mathrm{bc}$ & $5.6 \mathrm{~b}$ & $17.3 \mathrm{~b}$ \\
& SI5 & 16.7 & $23.1 \mathrm{bc}$ & $29.7 \mathrm{~b}$ & $27.5 \mathrm{~b}$ & $12.5 \mathrm{~b}$ & $24.0 \mathrm{~b}$ \\
& SI7 & 0.0 & $70.3 \mathrm{a}$ & $42.9 \mathrm{a}$ & $34.8 \mathrm{ab}$ & $16.7 \mathrm{~b}$ & $32.7 \mathrm{a}$ \\
& PI7 & 0.0 & $6.3 \mathrm{c}$ & $9.1 \mathrm{~b}$ & $11.8 \mathrm{c}$ & $5.0 \mathrm{~b}$ & $8.7 \mathrm{c}$ \\
& PI9 & 6.7 & $27.8 \mathrm{~b}$ & $31.8 \mathrm{ab}$ & $46.3 \mathrm{a}$ & $53.3 \mathrm{a}$ & $38.7 \mathrm{a}$ \\
R5.7 & & & & & & & \\
& NI & $10.0 \mathrm{~b}$ & 31.6 & 50.0 & $22.4 \mathrm{~b}$ & 35.7 & $26.0 \mathrm{~b}$ \\
& SI5 & $44.8 \mathrm{a}$ & 38.5 & 23.1 & $45.7 \mathrm{a}$ & 50.0 & $43.3 \mathrm{a}$ \\
& SI7 & $47.8 \mathrm{a}$ & 58.8 & 28.6 & $53.9 \mathrm{a}$ & 28.6 & $50.0 \mathrm{a}$ \\
& PI7 & $27.3 \mathrm{ab}$ & 25.0 & 40.0 & $25.0 \mathrm{a}$ & 25.0 & $24.7 \mathrm{~b}$ \\
& PI9 & $50 \mathrm{a}$ & 53.0 & 33.3 & $55.2 \mathrm{a}$ & 54.0 & $53.3 \mathrm{a}$ \\
\hline
\end{tabular}

Mean followed by same and without letters within a column of each stage are not significantly different Chi squaretest $(P<0.10)$.

Table 12. Occupation ratio of serotype USDA110 in nodule of each growth stage.

\begin{tabular}{ccc}
\hline \multirow{2}{*}{ Treatment } & \multicolumn{3}{c}{ Growth stage } \\
\cline { 2 - 3 } & V6.4 & R5.7 \\
\hline NI & $48.0 \mathrm{a}$ & $9.2 \mathrm{c}$ \\
SI5 & $50.0 \mathrm{a}$ & $16.3 \mathrm{~b}$ \\
SI7 & $39.1 \mathrm{ab}$ & $7.9 \mathrm{c}$ \\
PI7 & $48.0 \mathrm{a}$ & $28.4 \mathrm{a}$ \\
PI9 & $33.3 \mathrm{~b}$ & $10.1 \mathrm{c}$ \\
\hline
\end{tabular}

Table 13. Acetylene reduction activity (ARA: $\mu$ mole $\mathrm{g}^{-1} \mathrm{DW}$ ) at each growth stage.

\begin{tabular}{ccccccc}
\hline Tratment & $\begin{array}{c}\text { Pod number } \\
\mathrm{m}^{-2}\end{array}$ & $\begin{array}{c}\text { Seed number } \\
\text { pod }^{-1}\end{array}$ & Full seed ratio & $\begin{array}{c}100 \text { seed } \\
\text { g DW }\end{array}$ & $\begin{array}{c}\text { Yield } \\
\text { g DW m }^{-2}\end{array}$ & Yield index \\
\hline NI & 477.5 & 1.81 & 0.93 & 21.2 & $165.5 \mathrm{~b}$ & 0.57 \\
SI5 & 545.5 & 1.85 & 0.94 & 21.5 & $210.2 \mathrm{a}$ & 0.58 \\
SI7 & 527.5 & 1.80 & 0.92 & 22.7 & $195.9 \mathrm{a}$ & 0.55 \\
PI7 & 486.7 & 1.84 & 0.94 & 20.6 & $172.7 \mathrm{~b}$ & 0.57 \\
PI9 & 577.8 & 1.79 & 0.93 & 21.8 & $208.8 \mathrm{a}$ & 0.56 \\
\hline \multicolumn{7}{l}{ Mean followed by same and without letters within a column of each stage are not significantly different using LSD (P<0.10). }
\end{tabular}

Table 14. Seed yield and yield components of each treatment.

Consequently, in SI5, SI7, and PI9 plots, occupation of serotype USDA110 was significantly high vs. other treatments. Since greater fixed nitrogen was distributed for these treatments to pods and seeds, yield $\left(\mathrm{g} / \mathrm{m}^{2}\right)$ significantly increased. It was thought that the density of $10^{5}$ cells/seed was more effective at seed inoculation because there were no effect by increasing the inoculum above this density. And from the results of the PI9 plot, it was thought previ- 
ous inoculation using BM2 $\left(1.7 \times 10^{5}\right.$ cells/seed $)$ was effective in competition with the indigenous rhizobia for nodulation.

Previous work showed that to successfully compete with indigenous rhizobium, introduced inoculum must be 1000 times greater [1]. However, in Canada, standard inoculum for soybean, kidney bean, and pea were $10^{5}$ cells/seed [60]. Others have reported unsuccessful nodulation at high concentrations of B. japonicum USDA110 [68]. In this study, we demonstrated a significant increase in yield in both SI5 and SI7 treatments with inoculation concentrations of $10^{5}$ cell/seed and $1.7 \times 10^{5}$ cell/seed, respectively. Increased inoculum density above these levels did not increase seed yield. We concluded that it is possible to increase yield through the introduction of rhizobium species having greater nitrogen fixation rates.

\section{Author details}

Takeo Yamakawa ${ }^{1^{*}}$ and Yuichi Saeki ${ }^{2}$

*Address all correspondence to: yamakawa@agr.kyushu-u.ac.jp

1 Department of Biosciences \& Biotechnology, Faculty of Agriculture, Kyushu University, 6-10-1 Hakozaki, Higashi-ku, Fukuoka, Japan

2 Department of Biotechnology and Biosciences, Faculty of Agriculture, University of Miyazaki, Miyazaki, Japan

\section{References}

[1] Weaver RW., Frederick LR. Effect of Inoculum Rate on Competitive Nodulation of Glycine max L. Merrill. II. Field Studies. Agronomy Journal 1974: 66(2) 233-236.

[2] Kvien CS., Ham GE., Lambert JW. Recovery of Introduced Rhizobium japonicum Strains by Soybean Genotypes. Agronomy Journal 1981: 73(5) 900-905.

[3] Takahashi T., Ito A., Suzuki H. Interaction between Effective Bacteria and Host Plant. In: Ishizuka J. (ed.) Studies on Nodule Formation and Nitrogen Fixation in Legume Crops. Tokyo: Ministry of Agriculture, Forestry and Fisheries; 1996. p92-107.

[4] Maier RJ., Brill WJ. Mutant Slrams of Rhizohium japonicum with Increased Ability to Fix Nitrogen for Soybean. Science 1978: 201(4354) 448-450.

[5] Williams LE., Phillips DA. Increased Soybean Productivity with a Rhizobium japonicum Mutant. Crop Science 1983: 23(2) 246-250.

[6] Maier J., Graham L. Mutant Strains of Bradyrhizobium japonicum with Increased Symbiotic $\mathrm{N}_{2}$ Fixation Rates and Altered Mo Metabolism Properties. Applied Environmental Microbiology 1990: 56(8) 2341-2346. 
[7] Williams LF., Lynch LD. Inheritance of a Non-nodulating Character in the Soybean. Agronomy Journal 1954: 46(1) 28-29.

[8] Caldwell BE. Inheritance of a Strain-Specific Ineffective Nodulation in Soybeans. Crop Science 1966: 6(5) 427-428.

[9] Caldwell BE., Hinson K., Johnson HW. A Strain-Specific Ineffective Nodulation Reaction in the Soybean Glycine max L. Merrill. Crop Science 1966: 6(5) 495-496.

[10] Vest G. Rj3 A Gene Conditioning Ineffective Nodulation. Crop Science 1970: 10(1): 34-35.

[11] Vest G., Caldwell EB. Rj4 - A Gene Conditioning Ineffective Nodulation in Soybean. Crop Science 1972: 12(5) 692-693.

[12] Ishizuka J., Suemasu Y., Mizogami K. Prefarence of Rj-Soybean Cultivars for Bradyrhizobium japonicum for Nodulation. Soil Science and Plant Nutrition 1991: 37(1) 15-21.

[13] Ishizuka J., Yokoyama A., Suemasu Y. Relationship between Serotypes of Bradyrhizobium japonicum and Their Compatibility with Rj-Cultivars for Nodulation. Soil Science and Plant Nutrition 1991: 37(1) 23-30.

[14] Ishizuka J., Kim SD., Hussain AKMA., Yamakawa T. Soybean Preference for Bradyrhizobium japonicum for Nodulation. Isolation of $R j_{2} R j_{4}$-Lines from the Cross of Soybean Cvs. IAC-2 $\left(R j_{2}\right)$ and Hill $\left(R j_{4}\right)$. Soil Science and Plant Nutrition 1993: 39(1) 79-86.

[15] Yamakawa T., Eriguchi M., Hussain AKMA., Ishizuka J. Soybean Preference for Bradyrhizobium japonicum for Nodulation. Nodulation by $R j_{2} R j_{3} R j_{4}$-Genotypes Isolated from the Progenies of Cross of Soybean Cvs. IAC-2 $\left(R j_{2} R j_{3}\right)$ and Hill $\left(R j_{4}\right)$. Soil Science and Plant Nutrition 1999: 45(2) 461-469.

[16] Vincent J.M. A Manual for the Practical Study of the Root-Nodule Bacteria. IBP Handbook, No.15. Oxford; Blackwell Scientific Publications; 1970.

[17] Minamisawa K., Iino H., Saito N., Onodera S., Nakatuka Y., Nakazima S., Kubota M., Asami T. Determination of Genotype Group of Bradyrhizobium japonicum by Indole-3Acetic Production. Japanese Journal of Soil Science and Plant Nutrition 1992: 63(4) 459-462. (in Japanese)

[18] Owens LD., Wright DA. Production of the Soybean-Chlorosis Toxin by Rhizobium japonicum in Pure Culture. Plant Physiology 1965: 40(5) 931-933.

[19] Gordon SA., Weber RP. The Colorimetric Estimation of IAA. Plant Physiology 1951: 26(1) 192-195.

[20] Minamisawa K., Fukai K. Production of Indole-3-Acetic Acid by Bradyrhizobium japonicum: A Correlation with Genotype Grouping and Rhizobitoxine Production. Plant Cell Physiology 1991: 32(1) 1-9. 
[21] Haider J., Hussam AKMA., Ikeda M., Yamakawa T., Ishizuka J. Effects of Nitrate Application on Growth, Nodulation and Nitrogen Fixation of Nitrate-Tolerant Mutant of Soybean. Soil Science and Plant Nutrition 1991: 37(3) 521-529.

[22] Yamakawa T, Hussain AMKA, Ishizuka J. Soybean Preference for Bradyrhizobium japonicum for Nodulation. Occupation of Serogroup USDA110 in Nodules of Soybean Plants Harboring Various Rj-Genes Grown in a Field. Soil Science and Plant Nutrition 2003: 49(6) 835-841.

[23] Evans HI., Harker AR., Papen H., Russell SA., Hauns FI., Zuber M. Physiology, Biochemistry and Genetics of the Uptake Hydrogenase in Rhizobia. Annual Review of Microbiology 1987: 41 335-361.

[24] Cregan PB., Keyser HH. Host Restriction of Nodulation by Bradyrhizobium japonicum Strain USDA 123 in Soybean. Crop Science 1968: 26(5) 911-916.

[25] Saeki Y., Aimi N., Tsukamoto S., Yamakawa T., Nagatomo Y., Akao S. Diversity and Geographical Distribution of Indigenous Soybean-Nodulating Bradyrhizobia in Japan. Soil Science and Plant Nutrition 2006: 52(4) 418-426.

[26] Saeki Y., Ozumi S., Yamamoto A., Umehara Y., Hayashi M., Sigua GC. Change in Population Occupancy of Bradyrhizobia under Different Temperature Regimes. Microbes Environments 2010: 25(4) 309-312.

[27] Minami M., Yamakawa T., Yamamoto A., Akao S., Saeki Y. Estimation of Nodulation Tendency among Rj-Genotype Soybeans using the Bradyrhizobial Community Isolated from an Andosol. Soil Science and Plant Nutrition 2009: 55(1) 65-72.

[28] Saeki Y., Minami M., Yamamoto A., Akao S. Estimation of the Bacterial Community Diversity of Soybean-Nodulating Rhizobia Isolated from Rj-Genotype Soybean. Soil Science and Plant Nutrition 2008: 54(5) 718-724.

[29] Saeki Y., Akagi I., Takaki H., Nagatomo Y. Diversity of Indigenous Bradyrhizobium Strains Isolated from Three Different Rj-Soybean Cultivars in Terms of Randomly Amplified Polymorphic DNA and Intrinsic Antibiotic Resistance. Soil Science and Plant Nutrition 2000: 46(4) 917-926.

[30] Hiraishi A., Kamagata Y., Nakamura K. Polymerase Chain Reaction Amplification and Restriction Fragment Length Polymorphism Analysis of 16S rRNA Genes from Methanogens. Journal of Fermentation and Bioengineering 1995: 79(6) 523-529.

[31] Saeki Y., Aimi N., Hashimoto M., Tsukamoto S., Kaneko A., Yoshida N., Nagatomo Y., Akao S. Grouping of Bradyrhizobium USDA Strains by Sequence Analysis of 16S rDNA and 16S-23S rDNA Internal Transcribed Spacer Region. Soil Science and Plant Nutrition 2004: 50(4) 517-525.

[32] Nei M., Li HW. Mathematical Model for Studying Genetic Variation in Terms of Restriction Endonucleases. Proceeding of the National Academy of Sciences of the United States of America 1979: 76(10) 5269-5273. 
[33] Sakai M., Futamata H., Kim SJ., Matuguchi T. Effect of Soil Salinity on Population Structure of Fluorescent Pseudomonads in Spinach Rhizosphere. Soil Science and Plant Nutrition 1998: 44(4) 701-705.

[34] MacArthur RH. Patterns of Species Diversity. Biological Reviews 1965: 40(4) 510 533.

[35] Pielou EC. Ecological Diversity and Its Measurement. In: An Introduction to Mathematical Ecology. New York: John Wiley \& Sons Inc; 1969. p221-235.

[36] Kobayashi S. Multivariate Analysis of Biological Communities. Tokyo; Soju Shobo; 1995. (In Japanese.)

[37] Whittaker RH. Evolution and Measurement of Species Diversity. Taxon 1972: 21(2/3) 213-251.

[38] Shiro S., Yamamoto A., Umehara Y., Hayashi M., Yoshida N., Nishiwaki A., Yamakawa T., Saeki Y. Effect of Rj Genotype and Cultivation Temperature on the Community Structure of Soybean-Nodulating Bradyrhizobia. Applied Environmental Microbiology 2011: 78(4) 1243-1250.

[39] Zhang F., Smith LD. Effect of Low Root Temperature on the Early Stages of Symbiosis Establishment between Soybean (Glycine max (L.) Merr.) and Bradyrhizobium japonicum. Journal of Experimental Botany 1994: 45(10) 1467-1473.

[40] Zhang F., Smith LD. Genistein Accumulation in Soybean (Glycine max [L.] Merr.) Root Systems under Suboptimal Root Zone Temperatures. Journal of Experimental Botany 1996: 47(6) 785-792.

[41] Zhang F., Charles CT., Pan B., Smith LD. Inhibition of the Expression of Bradyrhizobium japonicum nod Genes at Low Temperatures. Soil Biology and Biochemistry 1996: 28(12) 1579-1583.

[42] Pan B., Smith LD. Genistein and Daidzein Concentrations and Contents in Seedling Roots of Three Soybean Cultivars Grown under Three Root Zone Temperatures. Journal of Agronomy and Crop Scence 1998: 180(2) 77-82.

[43] Yokoyama T. Effects of Temperature on Competition for Nodulation in Phylogenetically Different Bradyrhizobium Strains. Japanese Journal of Soil Science and Plant Nutrition 2005: 76(5) 599-607. (In Japanese with English summary.)

[44] Yokoyama T., Ando S., Murakami T., Imai H. Genetic Variability of the Common nod Gene in Soybean Bradyrhizobia Isolated in Thailand and Japan. Canadian Journal of Microbiology 1996: 42(12) 1209-1218.

[45] Duzan HM., Zhou X., Souleimanov A., Smith LD. Perception of Bradyrhizobium japonicum Nod Factor by Soybean [Glycine max (L.) Merr.] Root Hairs under Abiotic Stress Conditions. Journal of Experimental Botany 2004: 55(408) 2641-2646.

[46] Sadowsky MJ., Cregan PB., Guottfert M., Sharma A., Gerhold D., Rodriguez-Quinones F., Keyzer HH., Henneke H., Stacy G. The Bradyrhizobium japonicum nolA Gene 
and Its Involvement in the Genotype-Specific Nodulation of Soybeans. Proceeding of the National Academy of Sciences of the United States of America 1991: 88(2) 637-641.

[47] Lohrke SM., Day B., Kolli VS., Hancock R., Yuen JP., de Souza ML., Stacey G., Carlson R., Tong Z., Hur HG., Orf JH., Sadowsky MJ. The Bradyrhizobium japonicum noeD Gene: A Negatively Acting, Genotype Specific Nodulation Gene for Soybean. Molecular Plant-Microbe Interctions 1998: 11(6) 476- 488.

[48] Cole MA., Elkan GH. Transmissible Resistance to Penicillin G, Neomycin, and Chloramphenicol in Rhizobium japonicum. Antimicrobal Agents and Chemotherapy 1973: 4(3) 248-253.

[49] Sambrook J., Fritsch EF., Maniatis T. Molecular Cloning: A Laboratory Manual, 2nd edn. Cold Spring Harbor; 1989.

[50] Simon R., Prieffer U., Pühler A. A Broad Host Range Mobilization System for In Vivo Genetic Engineering: Transposon Mutagenesis in Gram-Negative Bacteria. Nature Biotechnology 1(9), 784-791, 1983.

[51] Herrero M., de Lorenzo V., Timmis KN. Transposon Vectors Containing Non-Antibiotic Resistance Selection Markers for Cloning and Stable Chromosomal Insertion of Foreign Genes in Gram-Negative Bacteria. Journal of Bacteriology 1990: 172(11) $6557-6567$.

[52] Kuykendall LD. Isolation and Identification of Genetically Marked Strains of Nitrogen-Fixing Microsymbionts of Soybean. In: Elkan GH (ed.) Symbiotic Nitrogen Fixation Technology. New York and Basel: Marcel Dekker, Inc; 1987. p205-220.

[53] Nakano Y., Yamakawa T., Ikeda M., Ishizuka J. Nodulation of Rj-Soybean Varieties with Rhizobium fredii USDA193 under Limited Supply of Nutrients. Soil Science and Plant Nutrition 1997: 43(4) 929-932.

[54] Kwon YM., Ricke SC. Efficient Amplification of Multiple Transposon-Flanking Sequences. Journal of Microbiological Methods 2000: 41(3) 195-199.

[55] Tsurumaru H., Yamakawa T., Tanaka M., Sakai M. Tn5 Mutants of Bradyrhizobium japonicum Is-1 with Altered Compatibility with $R j_{2}$-Soybean Cultivars. Soil Science and Plant Nutrition 2008: 54(2) 197-203, 2008.

[56] Kaneko T., Nakamura Y., Sato S., Minamisawa K., Uchiumi T., Sasamoto S., Watanabe A., Idesawa K., Iriguchi M., Kawashima K., Kohara M., Matsumoto M., Shimpo S., Tsuruoka H., Wada T., Yamada M., Tabata S. Complete Genomic Sequence of Nitrogen-fixing Symbiotic Bacterium Bradyrhizobium japonicum USDA110. DNA Reserch 2002: 9(6) 189-197.

[57] Kiessling U., Platzer M., Strauss M. Plasmid Rescue - A Tool for Reproducible Recovery of Genes from Transfected Mammalian Cells? Molecular and General Genetics 1984: 193(3) 513-519. 
[58] Tsurumaru H., Yamakawa T., Tanaka M., Sakai M. The Efficient Strategy of Plasmid Rescue from Tn5 Mutants Derived from Bradyrhizobium japonicum Is-1, Based on Whole Genome Sequence Information of Strain USDA110. Journal of the Faculty of Agriculture, Kyushu University 2008: 53(1) 27-31.

[59] Hardarson G., Golbs M., Danso SKA. Nitrogen Fixation in Soybeans (Glycine max L. Merrill) as Affected by Nodulation Patterns. Soil Biology and Biochemistry 1989: 21(6) 783-787.

[60] Lohrke SM., Madrzak CJ., Hur H., Judd AK., Orf JH., Sadowsky MJ. Inoculum Density-Dependent Restriction of Nodulation in the Soybean-Bradyrhizobium japonicum Symbiosis. Symbiosis 2000: 29(1) 59-70.

[61] Yamakawa T., Tanaka M., Sakai M., Sarr PS. Genetic Grouping of Bradyrhizobium Strains Compatible with Soybean (Glycine max L. Merr.) Harboring Rj-gene by AFLPfingerprinting Analysis. Journal of the Faculty of Agriculture, Kyushu University 2011: 56(2) 223-229.

[62] Wei X., Bauer WD. Tn5-Induced and Spontaneous Switching of Sinorhizobium meliloti to Faster-Swarming Behavior. Applied and Environmental Microbiology 1999: 65(3) 1228-1235.

[63] Rosen BP., Bhattacharjee H., Shi W. Mechanisms of Metalloregulation of an AnionTranslocating ATPase. Journal of Bioenergetics and Biomembranes 1995: 27(1) 85-91.

[64] Ulusu NN., Tezcan EF. Cold Shock Proteins. Turkish Journal of Medical Sciences 2001: 31(4), 283-290.

[65] Judd AK., Sadowsky MJ., Bhagwat AA., Cregan PB., Liu RL. Isolation of a Bradyrhizobium japonicum Serogroup 123 Mutant Which Has an Extended Host Range for Nodulation-Restricting Soybean Genotypes. FEMS Microbiology Letters 1993: 106(2) 205-210.

[66] Fukushima Y., Yamakawa, T. Effect of Difference of Inoculation Method and Inoculum Density of Bradyrhizobium japonicum USDA110 on Production of Soybean (Glycine $\max$ L. Merr.), Science bulletin of the Faculty of Agriculture, Kyushu University 2006: 61(2) 171-176. (in Japanese with English summary)

[67] Fehr WR., Cavines, CE., Burmood DT., Pennington JS. Stage of Development Descriptions for Soybeans, Glycine $\max$ (L) Merrill. Crop Science 1971: 11(6) 929-931.

[68] Smith RS. Legume Inoculant Formulation and Application. Canadian Journal of Microbiology 1992: 38(6) 485-492. 